\title{
Development of novel hybrid machine learning models for monthly thunderstorm frequency prediction over Bangladesh
}

\section{Md. Abul Kalam Azad}

Begum Rokeya University

A R M Towfiqul Islam ( $\boldsymbol{\nabla}$ towfiq_dm@brur.ac.bd)

Begum Rokeya University https://orcid.org/0000-0001-5779-1382

\section{Md. Siddiqur Rahman}

Begum Rokeya University

Kurratul Ayen

Begum Rokeya University

\section{Research Article}

Keywords: Thunderstorm, Hybrid model, Ensemble empirical mode decomposition, Sensitivity analysis, Random Forest, Bangladesh

Posted Date: February 10th, 2021

DOl: https://doi.org/10.21203/rs.3.rs-204328/v1

License: (c) (i) This work is licensed under a Creative Commons Attribution 4.0 International License. Read Full License

Version of Record: A version of this preprint was published at Natural Hazards on April 15th, 2021. See the published version at https://doi.org/10.1007/s11069-021-04722-9. 


\title{
Development of novel hybrid machine learning models for monthly thunderstorm frequency prediction over Bangladesh
}

\author{
4 Md. Abul Kalam Azad ${ }^{1 *}$, Abu Reza Md. Towfiqul Islam ${ }^{1 *}$, Md. Siddiqur Rahman ${ }^{1}$, Kurratul Ayen $^{1}$ \\ $5 \quad{ }^{1}$ Department of Disaster Management, Begum Rokeya University, Rangpur 5400, Bangladesh

\section{Abstract}

Accurate thunderstorm frequency (TSF) prediction is of great significance under climate extremes for reducing potential damages. However, TSF prediction has received little attention because a thunderstorm event is a combination of intricate and unique weather scenarios with high instability, making it difficult to predict. To close this gap, we proposed a novel hybrid machine learning model through hybridization of data pre-processing Ensemble Empirical Mode Decomposition (EEMD) with two state-of-arts models namely artificial neural network (EEMD-ANN), support vector machine (EEMD-SVM) for TSF prediction at three categories of yearly frequencies over Bangladesh. We were demarcated the yearly TSF datasets into three categories for the period 1981-2016 recorded at 28 sites; high (March-June), moderate (July-October), and low (November-February) 
32 SVM hybrid models showed $8.02 \%-22.48 \%$ higher performance precision in terms of root mean square error 33 (RMSE) compared to other models at high, moderate and low-frequency categories. Eleven out of 21 input parameters were selected based on the Random Forest (RF) variable importance analysis. The sensitivity analysis results showed that each input parameter was positively contributed to building the best model of each category and thunderstorm days are the most contributing parameters influencing TSF prediction. The proposed hybrid models outperformed the conventional models where EEMD-ANN is the most skillful for high TSF prediction, and EEMD-SVM is for moderate and low TSF prediction. The findings indicate the potential of hybridization of EEMD with the conventional models for improving prediction precision. The hybrid model developed in this work can be adopted for TSF prediction in Bangladesh as well as different parts of the world.

41 Keywords: Thunderstorm; Hybrid model; Ensemble empirical mode decomposition; Sensitivity analysis,

\section{Random Forest, Bangladesh}

\section{1. Introduction}

44 Thunderstorms are spectacular mesoscale phenomena that affect the environment and pose a severe threat to life, economy, agriculture, and infrastructures. A thunderstorm event results from a turbulent convective activity, which may bring about heavy rainfall, lightning, hail, tornadoes, and thunder (Islam et al., 2020). Thunderstorms occur in almost every region of the world because of meteorological instability and strong moisture convergence, which causes serious convections. It usually exists for less than an hour and typically has varying sizes ranging from a few kilometers to a few hundred kilometers (Saha and Quadir 2016). It is now a well-acknowledged fact that the climate system is getting warmer, which has implications for thunderstorm occurrences (Allen et al., 2014; Trenberth et al., 2007). Severe thunderstorms frequency is likely to increase in the $21^{\text {st }}$ century due to the increasing convective instability (Rädler et al., 2019). Therefore, it is essential to predict the number of

54 location. Predicting the number of thunderstorm phenomena could provide insights about future thunderstorm incidents under the climate change scenario.

56 Thunderstorm frequency (TSF) can be defined as the number of thunderstorm occurrences in a given location 57 over a day, month, season, or annum. It is estimated that daily TSF is nearly 45,000 and annually 16 million 
worldwide (Siddiqui and Rashid 2008). Many parts of South Asia experience higher TSF during the summer months (March-May) when high temperatures prevail at lower levels create a volatile atmosphere. Each year Bangladesh and its surroundings witness high TSF, especially during the pre-monsoon and early months of the monsoon season; however, thunderstorms occur in all seasons. Spatially, TSF is highest in the northeastern part

62 and less in the southeastern and northwestern parts of Bangladesh (Mannan et al., 2016). Before 1981, the 63 country endured thunderstorm strikes in about nine days in May, which later rose to 12 days. Besides, thunderstorms associated disasters cause severe damage to agricultural yields and infrastructures and lives on the ground and in aviation. Due to the exorbitant impact of thunderstorms on human life and the economy, the Government of Bangladesh declared it a natural disaster on 17 May 2016 (Wahiduzzaman et al., 2020). In contrast, thunderstorms bring crucial rainfall during the dry season, which benefits the country's crop production and cleans the air from dust, haze, and pollutants. A TSF prediction model can help prepare and design a more useful crop calendar adaptive to thunderstorm events. Besides, a TSF prediction model is essential for policymakers to adopt a mitigation plan for reducing the potential damages of thunderstorm casualties.

71 Thunderstorm prediction is a challenging task due to its small spatiotemporal extension, and the event is a 72 combination of very complex and unique weather scenarios, which are highly unstable. Despite the challenges, 73 many a researcher has attempted to predict thunderstorms worldwide, e.g., Jacovides and Yonetani (1990) in 74 Cyprus; Mills and Colquhoun (1998) in Australia; Haklander and Delden (2003) in Netherland; Manzato (2007) 75 in Italy; Zhen-hui et al. (2013) in China; Ali et al. (2011) in Malaysia; Litta et al. (2013) and Meher et al. (2019) in India; Collins and Tissot (2015) in the USA; Dowdy (2016) in the temperate and tropical regions; Osuri et al. 77 (2017) in Indian monsoon region; Rädler et al. (2019) in Europe; Chen et al. (2020) in Taiwan; Kulikov et al. 78 (2020) in Russia; Bouttier and Marchal (2020) in Western Europe; Islam et al. (2020) in Bangladesh. A variety 79 of approaches have been taken in those studies. For example, Collins and Tissot (2015) used and compared an 80 ANN and MLR model for thunderstorms prediction within $400 \mathrm{~km}^{2}$ of South Texas; Rädler et al. (2019) used 81 an ensemble of 14 regional climate models such as AR-CHaMo models, EURO-CORDEX model to assess the 82 changes in the frequency of thunderstorm. Most of the studies have focused on Numerical Weather Prediction 83 (NWP) modeling or forecasting of a single thunderstorm event on an hourly basis based on the convective 84 indices. However, studies focused on predicting monthly TSF based on the convective indices and other 
thunderstorm-related parameters are still scarce in the literature (Islam et al., 2020). In the present study, we

86 have employed machine learning models including Artificial Neural Network (ANN), Support Vector Machine

87 (SVM), incorporated with Ensemble Empirical Mode Decomposition (EEMD), and Auto-Regressive Integrated

88 Moving Average (ARIMA) modeling to predict the monthly TSF over Bangladesh.

89 Among the machine learning models, ANN is a powerful model that can identify complex inherent nonlinear

90 relationships between responses and predictors. Therefore, ANN models have drawn attention in the

91 thunderstorm forecasting community (Manzato. 2007; Collins and Tissot, 2015; Litta et al., 2013). SVM is also

92 a useful prediction technique that was used before in thunderstorm prediction (Qiu et al., 2010; Zhen-hui et al.,

93 2013). The time series model like ARIMA is widely used because it can characterize nonlinear data; this model

94 was also applied previously in thunderstorm prediction (Islam et al., 2020). Though these models are not always

95 efficient enough to predict a target dataset accurately. Due to this reason, many researchers have developed

96 techniques that adjoin several types of methods to obtain more accuracy in their prediction (Chen and Letchford.

97 2007; Gao and Stensrud. 2014; Solari et al., 2017; Suparta and Putro. 2018; Bouttier and Marchal. 2020;

98 Kamangir et al., 2020). The hybrid EEMD integrated machine learning models have successfully applied in 99 different fields of studies, e.g., runoff (Tan et al., 2018); streamflow forecasting (Zhang et al. 2015); rainfall forecasting (Johny et al. 2020) wind speed forecasting (Yu, 2020); groundwater level (Gong et al., 2018). However, TSF prediction has received little attention in the existing literature due to its complicated nature and unique weather feature with high instability, making it difficult to predict. Our work fills this research gap in literature. Therefore, a hybrid EEMD-ANN and EEMD-SVM models, the combination of an ensemble empirical mode decomposition (EEMD) with an ANN and SVM model, are proposed as effective methods to predict monthly TSF. In this study, widely used convective indices and thunderstorm-related variables were used as input parameters. The EEMD-ANN and EEMD-SVM prediction results were compared with three conventional 107 prediction methods, e.g., ANN, SVM, and ARIMA, based on five performance evaluation metrics, i.e., 108 Coefficient of determination $\left(\mathrm{R}^{2}\right)$, Root Mean Square Error (RMSE), Mean Absolute Error (MAE), Mean Absolute Percentage Error (MAPE), Index of Agreement (IA) along with the Taylor diagram. Even though machine learning models can solve prediction problems with reasonable accuracy, their predictive capability relies significantly on the input data quality. In such a case, sensitivity analysis can help identify which input 
112 parameter is remarkable in building an ideal model. So, sensitivity analysis is employed in this study to improve

113 the performance of the models.

114 This study's primary objective is to predict and evaluate the performance of the monthly TSF based on the 115 convective and thunderstorm-related indices. Compare to other earlier studies, our work has two novel aspects.

116 First, we develop hybrid machine learning models to predict monthly TSF at three frequency metrics over

117 Bangladesh for the first time in literature. Second, this study identifies the most contributing parameters

118 influencing TSF prediction and select optimal input parameters using Random Forest model. It is hoped that the 119 novel hybrid model proposed in this work would able to address the challenge of complicated nature of 120 thunderstorm event due to its high instability and randomness.

\section{$121 \quad 2$. Study area and data sources}

122 The site selected for this research is Bangladesh, a part of Southeast Asia, geographically located between $20^{\circ}$ $12334^{\prime}$ to $26^{\circ} 38^{\prime}$ North latitude and $88^{\circ} 01^{\prime}$ to $92^{\circ} 42^{\prime}$ East longitude. Bangladesh is the biggest deltaic country in 124 the world, occupying 147,570 sq. km area. The three vigorous rivers, Padma, Jamuna, and Meghna, and their 125 tributaries encompass $80 \%$ of Bangladesh's floodplains, leaving out the hilly parts. The geographical features of 126 this narrow flat lowland are very well suited for convection, as the moisture conveyed by the monsoon winds 127 from the highly elevated regions and the Bay of Bengal causes the development of convection (Ahmed et al., 128 2017). Here, the monsoon is probably the controlling feature of climatic variability (Islam et al., 2020), portrayed by pelter-bearing breezes, humbly warm temperatures, and high moisture in the air. As an outcome, thunderstorms, floods, and tidal floods are regular incidents in this country. There are three prominent seasons observed in Bangladesh, which are premonsoon, monsoon, and post-monsoon.

132 In this study, monthly TSF and TSD data were collected from 28 stations (Fig. 1) of the Bangladesh 133 Meteorological Department (BMD) ranged from 1981 to 2016. There are more meteorological stations in 134 Bangladesh, but those stations do not have long term records of thunderstorms, and few stations have excessive 135 missing data. Therefore, we have excluded those stations. Although some of the selected stations have few 136 missing data, we have filled them by obtaining the nearest station's value. Table $\mathrm{S} 1$ contains the missing data 137 information. Thunderstorm frequencies are recorded eight times per day in each station of BMD with a threehour interval according to the World Meteorological Organization (WMO) standard hour. The number of TSF 
observations recorded per day is regarded as the daily TSF. From the daily observations, monthly TSF is computed for each station. Description of the 28 meteorological stations of BMD and an overview of the annual TSF data are given in Table 1. The number of days with thunderstorm observations in a month is regarded as monthly TSD. Daily precipitation data was also collected from the same 28 stations of the BMD from 1981 to 2016. We then converted the daily precipitation into monthly average data and used them as predictors for the model building.

Single point data of Dew/Frost Point at 2 meters (DP), Relative Humidity at 2 meters (RH), Wind Speed range at 50 meters (WS50), and Earth Skin Temperature (ST) data were used as a predictor in building TSF prediction model. These parameters were obtained for the specific latitude and longitude of the selected 28 stations from the NASA Langley Research Center Atmospheric Science Data Center Surface Meteorological and Solar Energy (SSE) web portal supported by the NASA LaRC POWER Project (https://power.larc.nasa.gov/data-accessviewer/), which has a $0.5^{\circ} \times 0.5^{\circ}$ gridded global dataset. Moreover, the monthly averaged CAPE, Convective Rain Rate (CRR), Convective Precipitation (CPRCP), K Index (KI), and Total Totals (TT) were obtained from Climate Data Store (CDS) of Copernicus Climate Change Service (https://cds-dev.copernicusclimate.eu/cdsapp\#!/dataset/reanalysis-era5-single-levels-monthly-means?tab=overview). We have calculated the average of 28 stations for all the data and then used them as country average because this approach helps the future assumption of thunderstorm frequency within a large area. Table 2 corresponds to the descriptions of the datasets used in this study.

For convenience in predicting monthly TSF accurately, we have classified all the data in three categories of timeseries, e.g., HTSF (High Thunderstorm Frequency; containing high-frequency months of March, April, May, June), MTSF (Moderate Thunderstorm Frequency; containing moderate-frequency months of July, August, September, October), and LTSF months (Low Thunderstorm Frequency; having low-frequency months of November, December, January, February). This classification helps differentiate the months with high, moderate, and low TSF, and thus, it reduces abrupt fluctuations in the time-series, which increases the prediction accuracy.

\section{Methods used}

\subsection{Parameter Selection}


The input parameters were selected based on a Random Forest (RF) relative importance technique performed in

167 Salford Predictive Modeler 8.2. The RF algorithm is a popular and highly flexible supervised artificial intelligence applied to measure the importance of various contributing factors (Rahman et al., 2020). The RF method details can be found in the literature (Rahman and Islam, 2019; Salam and Islam, 2020). We have initially considered 21 input parameters and tested different combinations among them, but some of the parameters were

171 not suitable enough to efficiently predict TSF (Fig. S1). We have excluded 10 of the initially considered 172 parameters affecting the model performances and finalize 11 input parameters (Table 2) for model building. The 173 excluded parameters were Lifted Index (LI), maximum temperature (MaxT), precipitable water (PRW), diurnal 174 temperature (DT), specific humidity (SH), wind speed range at 10 meters (WS10), minimum temperature 175 (MinT), V component of wind (VCW), U component of wind (UCW), and surface pressure (SP). CAPE, CPRCP, CRR, DP, KI, PRCP, RH, ST, TSD, TT, and WS50 were the selected parameters for constructing prediction models. These parameters also have a high correlation with TSF (Fig. S2). Among the selected input parameters,

178 CAPE, KI, and TT are well known for their potentiality in predicting thunderstorm events (Vujovic et al., 2015; 179 Islam et al., 2020).

\subsection{Artificial Neural Network (ANN)}

Artificial Neural Network (ANN) is one of the most employed techniques for modeling accurate predictions to solve complex and nonlinear problems (Phuong et al., 2017; Alizadeh et al., 2018, Pham et al., 2019). ANNs are data processing systems that exploit learning algorithms to imitate knowledge and save this knowledge in weighted connections, similar to a human brain (Pradhan and Lee, 2010; Boateng et al., 2019). An ANN has numerous processing components called neurons (Boateng et al., 2019). The data are processed by the neurons and then feed-forwarded to the subsequent layer. Corresponding links between layers connect these neurons. On each connecting link, there is a numeric weight. An ANN structure consists of three main layers, e.g., input layers, hidden layers, and output layers. The input layer contains the variables used for model construction; the hidden layers analyze the interconnection between the input and the output parameters based on algorithms, and the output layer represents the predicted variables.

Unlike statistical models, ANNs can automatically synthesize their weights to elevate their attitude. 192 (Boussabaine, 1996). ANN is like a 'black box' which lacks self-explanation. As a result, both ANNs and 
statistical approaches can be ensembled into a robust and potent methodological platform despite their 194 differences (Karlaftis and Vlahogianni, 2011). At first, an ANN model has to be trained with an acquainted 195 dataset called the 'training' dataset. The model will then 'learn' by synthesizing the neurons' numerical weights regarding the errors between the predicted output values and the target output values through the training process.

197 After the training period, the neural network delivers a model that can predict a target value from a specificity 198 input value. This research has used a backpropagation based neural network regression approach to predict 199 thunderstorm frequency. Here, we have used 11 variables as input parameters and two layers in the hidden unit200 the 1st hidden layer composed of 4 neurons and the 2nd layer consisting of 2 neurons (Fig. 2). We have set the

201 learning rate to 0.1 while using the sigmoid function as the activation function. A neural network model can be 202 expressed in mathematical form as Eq.

203

$$
y(x)=K\left(\sum_{j=1}^{n} w_{j}(p) \cdot x_{j}(p)+c\right)
$$

204 Where,

$205 x_{j}(p)=$ Input variable in discrete-time $\mathrm{t}$

$206 y(x)=$ Predicted thunderstorm frequency

$207 n=$ Hidden neuron by trial

$208 w_{j}(p)=$ Weight that connects the $\mathrm{i}^{\text {th }}$ neuron in the input layer

$209 c=$ Neuronal bias

$210 \quad K()=$. Hidden transfer function

\section{$211 \quad 3.3$ Support Vector Machine (SVM)}

212 SVM, one of the most successful forecasting methods in recent years, was first proposed by Vapnik (1995). It is 213 remarkably capable of handling small-sized datasets and nonlinear problems (Liu and Wang, 2016; Ghimire et 214 al., 2019). So, it has been widely applied in regression modeling. It is one of the most effective predicting tools 215 often used as an alternative approach to ANN. The SVM approximates structural risk minimization based on 216 statistical learning theory (Meng et al., 2019) rather than empirical risk minimization (Huang et., 2014). The

217 SVM description is avoided in this paper because many documents and books have described SVM theory in 

idea is using the maximum margin algorithm (Pham et al., 2019), which searches for a hyperplane with the largest separating margin between the observed data. SVM can simplify an intricate problem by mapping the complicated nonlinear problem input factors into high-dimension space with kernel functions, transforming the complicated nonlinear problem into a linear problem. This process can find the optical function to fit the observations while avoiding overfitting to maintain the model generality. The useful and popular SVM kernel functions are linear, polynomial, sigmoid, Radial Basis Function (RBF), and so on. This research employs SVM as a regression technique that uses RBF:

$$
L\left(m, m_{j}\right)=\exp \left(-\frac{\left\|m-m_{j}\right\|^{2}}{2 \varphi^{2}}\right)
$$

where $\varphi$ represents the Gaussian noise level of standard deviation.

\subsection{Autoregressive Integrated Moving Average (ARIMA)}

ARIMA models are widely employed statistical prediction techniques because of their ability to handle nonstationary series efficiently. ARIMA modeling's basic idea is, here, the examined time series is linear and follows a particular normal distribution (Box and Jenkins, 1970). In a traditional ARIMA (p, d, q) model, p is autoregressive (AR), $d$ is the number of differences from the actual time-series data to make it stationary, and $q$ is moving average (MA). The standard equation for ARIMA models is as follows:

$$
d_{t}=\sum_{i=1}^{p} f_{i} d_{t-1}+\sum_{j=1}^{q} \theta_{j} e_{t-j}+\tau_{t}
$$

where $d_{t}$ is the observed value at time $t, f_{i}$ is the $i^{\text {th }}$ number of autoregressive parameter, $\theta_{j}$ is the $j^{\text {th }}$ number of moving average parameter and $\tau_{t}$ is the error at time $t$. In this study, the Box-Jenkins methodology is used to formulate the ARIMA $(1,1,1)(1,0,0)$ models for fitting TSF. This methodology comprises model identification, parameter estimation, and testing residual and forecast. A detailed description of the ARIMA model can be found in the literature (Contreras et al., 2003; Shadab et al., 2020).

\subsection{Ensemble Empirical Mode Decomposition (EEMD)}

Based on Hilbert-Huang Transform (HHT), Huang et al. (1998) first proposed Empirical Mode Decomposition 
advantages: 1. EMD is a highly efficient and adaptive method for nonlinear and non-stable signals (Chen et al., 2021). 2. HHT is fully adaptive by initially introducing the intrinsic mode functions (IMFs), which is unlike the

244 Wavelet Transform or Fourier Transform that needs a pre-determined basis. The brief mathematical process of the EMD can be found in the literature (Zhou et al., 2014; Wang et al., 2015; Fan et al., 2020). However, few of these IMFs may contain dramatic oscillations of different scales called "mode mixing" (Chen et al., 2021). This

247 inconvenience can make these IMFs lose their physical signification and make the EMD algorithm less robust 248 (Chen et al., 2021). The Ensemble Empirical Mode Decomposition (EEMD) was subsequently proposed by Wu and Huang (2009) to vanquish these shortcomings, adding a Gaussian white noise into the raw data series. It enables EEMD to automatically attribute signals with different time scales to the precise reference scales. In consequence, the correlation between the resultant IMFs and the raw series significantly improved. The processes of EEMD are as follows:

253 1. Add the normally distributed Gaussian white noise $\omega(t)$ to the target series $f(t)$ to get a new signal $F(t): F(t)=f(t)+\omega(t)$

2. Decompose $F(t)$ using EMD method. Obtain IMFs $C_{i}(t)$ and the residual $r(t)$ :

$$
F(t)=\sum_{i=1}^{n} C_{i}(t)+r(t)
$$

257 3. Adding different white noise sequence to the same raw series and repeat the above steps;

258 4. Since the mean value of Gaussian white noise is equal to zero, the IMFs obtained are integrated and averaged 259 as the final result:

$$
\overline{I M F}=\frac{1}{N} \sum_{m=1}^{N} C_{j, m}
$$
where $C_{j, m}$ represents the $j t h$ IMFs from the $m$ th time, $N$ denotes the number of the added white noise sequences. Resolved by the above process, we have obtained six IMFs in total from the raw data series.

\subsection{Hybrid Model building}

In weather prediction, predicting thunderstorms is one of the most challenging tasks because of the implicit nonlinearity of thunderstorms' physics and dynamics (Litta et al., 2013). A problem with ANN, SVM, and other linear and nonlinear prediction models is that they cannot accurately handle nonstationary data. To solve the 

3(a-c). In each category's case, we have selected the first three IMFs as predictors of the hybrid models with the other meteorological predictors. The value of IMF1, IMF2, and IMF3 are more relevant to the original series, and they are the most nonlinear components of their respective series. On the contrary, the value of IMF4, IMF5,

272 and IMF6 is minimal. The residuals' value is not entirely relevant, so that their contributions are lesser to fit the 273 model, indicating difficulty in predicting the TSF more accurately. Besides, the correlation analysis (Table 3) 274 suggested that the first three IMFs are the essential variables in predicting monthly TSF. Therefore, using these 275 sub-series in building the models might enhance the performances by giving useful information on several resolution levels. Fig. (4) demonstrates the methodological procedures of the EEMD-ANN and EEMD SVM

277 prediction models. As seen in Fig. (4), the main steps of the presented EEMD-ANN or EEMD-SVM prediction can be summarized as follows:

279 Step 1: Decompose the original time series into a finite set of IMFs and a residue using EEMD.

280 Step 2: Eliminate the irrelevant or redundant IMFs and residue and select the IMFs with the highest frequency 281 bands and a more significant correlation with the original series.

282 Step 3: Combine the selected IMF with other input parameters and then apply the ANN or SVM model to 283 construct a prediction model for predicting TSF.

284 Step: 4 Obtain the predicted output by the models.

3.7 Model performance evaluation

286 The performance of each prediction model is evaluated using the following metrics. By letting $\delta_{t}$ represent the 287 reference values, $\hat{\delta}_{t}$ represents the predicted values at time $t$, and $\bar{\delta}$ denotes the mean of the reference values. Coefficient of determination $\left(R^{2}\right)$

$R^{2}$ is the Coefficient of determination, which is a number between 0 and +1 . It measures the degree of alignment between two parameters; in our case, the reference data $\left(\delta_{t}\right)$ and the predicted data $\left(\hat{\delta}_{t}\right)$. It quantifies how well future outcomes are likely to be predicted by the model. The Coefficient of determination is calculated according to the formula as follows: 


$$
R^{2}=1-\frac{\sum_{i=1}^{N}\left(\delta_{t}-\hat{\delta}_{t}\right)^{2}}{\sum_{i=1}^{N}\left(\delta_{t}-\bar{\delta}\right)^{2}}
$$

293 where $\bar{\delta}$ represents the average of the reference values.

294 Root Mean Square Error (RMSE)

295 The second statistical metric RMSE is defined as follows:

$$
R M S E=\sqrt{\frac{1}{N} \sum_{i=1}^{N}\left(\delta_{i}-\hat{\delta}_{i}\right)^{2}}
$$

296 where $N$ is the number of points in the test dataset.

297 Mean Absolute Error (MAE.)

298 The third statistical metric, namely, the MAE, can be defined as follows:

$$
M A E=\frac{1}{N} \sum_{i=1}^{N}\left|\delta_{i}-\hat{\delta}_{i}\right|
$$

299 According to Eq. (), the $M A E$ is the average of the absolute error between $\delta_{i}$ and $\hat{\delta}_{i}(i=1,2, \cdots, n)$.

300 Mean Absolute Percentage Error (MAPE)

301 The fourth criterion is $M A P E$, which is used to compute the relative error between $\left|\delta_{i}-\hat{\delta}_{i}\right|$ and $\left|\delta_{i}\right|(i=$

$3021,2, \cdots, n)$, which is defined as

$$
M A P E=\frac{1}{N} \sum_{i=1}^{N} \frac{\left|\delta_{i}-\hat{\delta}_{i}\right|}{\left|\delta_{i}\right|} \times 100 \%
$$

\section{Index of Agreement (IA.)}

305 The $I A$ is used in this study and is defined as follows:

$$
I A=1-\frac{\sum_{i=1}^{N}\left(\hat{\delta}_{i}-\delta_{i}\right)^{2}}{\sum_{i=1}^{N}\left(\left|\hat{\delta}_{i}-\bar{\delta}\right|+\left|\delta_{i}-\bar{\delta}\right|\right)^{2}}
$$

The $I A$ is a dimensionless metric used in comparing different models. The outcome value of $I A$ is always between

0 and 1 . For a "perfect" model, the $\mathrm{R}^{2}$ and $I A$ are equivalent to 1 , and the $M A E, M A P E$, and $R M S E$ are equal to 
0 . The three commonly used metrics, i.e., MAE, MAPE, and RMSE, all quantify the differences between the predicted and observed concentrations. However, the RMSE is more sensitive to extreme values, and the MAPE is sensitive to small values because of the power term. $I A$ summarizes the similarity between the predicted and

311 observed propensities.

\section{Taylor Diagram}

313 Another model performance evaluation technique, "Taylor diagram," is used in this study. This technique is 314 widely used to compare model data and tracking changes in model performances. The mathematical theory to 315 construct the diagram can be found in the literature (Taylor, 2001; Pakalidou and Karacosta, 2018). The diagram 316 provides the degree of similarity between the observed point and the test point. The closest the test point to the 317 observed point, the highest the accuracy of the model.

\section{$318 \quad 3.8$ Sensitivity Analysis}

319 In this section, the sensitivity analysis of the input parameters was measured for the best performing model of each season using the following equation:

$$
\text { sensitivity }=\frac{R^{2}-\bar{R}^{2}}{R^{2}} \times 100
$$

where $R^{2}$ is the square of the correlation coefficient of the best prediction model and $\bar{R}^{2}$ is the square of the

324 correlation coefficient of the predicted model when a specific parameter is excluded from the model.

\section{4. Results}

\subsection{Comparative analysis}

327 In this section, the prediction results are presented along with a comparison of model performance metrics 328 among the predicted outputs from different models.

329 Fig. (5a) depicts the prediction results of HTSF using ANN, SVM, EEMD-ANN, EEMD-SVM, and 330 ARIMA models of the testing dataset. In general, the hydrograph illustrates that all the models except for 331 ARIMA have an excellent performance for simulating the monthly TSF. Moreover, Fig. (5b) shows the 332 scatter plots of prediction by these models, which indicates that the EEMD-ANN and EEMD-SVM model 333 have the best performance for predicting the monthly TSF. Here, for EEMD-ANN and EEMD-SVM, the 
least square fitting line is slightly closest to the best possible 45-degree fitting line than ANN, SVM, and ARIMA. From Fig (5a) and Fig (5b), it is not clear which model performs better between EEMD-ANN and EEMD-SVM, as both are very close.

337 It is evident from Fig. (5c) that EEMD-ANN generated the highest value of CC and lowered centered RMS 338 difference, while the other hybrid model EEMD-SVM was approximately equal in this regard. Comparing 339 the models' standard deviation suggests that the EEMD-ANN and EEMD-SVM models were more in 340 agreement and closer to observed values than the conventional ANN and SVM. It can also be seen in Fig. 341 (5c) that the EEMD-ANN has the standard deviation relative to the observed, but the traditional ANN has a standard deviation less than the observed. It shows that the hybrid EEMD-ANN outperforms classic ANN. Here also, the ARIMA model has the furthest distance from the reference data.

It can be observed from Table 4 that the EEMD-SVM model has a decent performance, acquiring good $\mathrm{R}^{2}$, training, and testing RMSE, MAE, MAPE, and IA values of 0.978, 1.364, 1.367, 1.095, 8.475, and 0.994, respectively. The ANN and SVM models have also acquired a good $\mathrm{R}^{2}$, training RMSE, testing RMSE, MAE, MAPE, and IA of 0.973 and $0.964,1.478$, and 1.67, 1.562 and 1.777, 1.099 and 1.446, 6.049 and 9.481, 0.992 and 0.99, respectively. ARIMA model has the worst performance compared with the other models, as observed in Table 4. The EEMD-ANN model has acquired the best score in all the validation metrics, gaining the best $\mathrm{R}^{2}$, training, and testing RMSE, MAE, MAPE, and IA values of 0.982, 1.177, $1.241,0.917,5.738$, and 0.995 , respectively. It increases the $\mathrm{R}^{2}$ and IA by $1 \%$ and $0.3 \%$ and reduces the training RMSE, testing RMSE, MAE, and MAPE by 20.34\%, 20.58\%, 16.52\%, and $0.31 \%$, respectively, compared to the conventional ANN.

354 The hydrograph of the MTSF prediction results of the testing dataset is presented in Fig. (6a). Again, the 355 hydrograph demonstrates that all the approaches except ARIMA have a decent performance in predicting 356 the monthly MTSF. The scatterplot of the predicted outputs suggests that the EEMD-ANN and EEMD357 SVM approaches have the closest least-square fitting line to the 45-degree line (Fig. 6b).

358 The Taylor diagram (Fig. 6c) suggests that the EEMD-ANN and EEMD-SVM have performed better than 359 conventional ANN, SVM, and ARIMA. For the hybrid models, the correlation coefficient is $>0.95$, while 
for the conventional models, it is $<0.95$. The lower centered RMS difference also confirms that the hybrid models are more in agreement than the conventional models. It is immensely challenging to find out the better model between the hybrid models as both the models have performed almost equally.

363 The validation metrics from Table 4 confirms that conventional ANN and SVM are remarkably inferior to 364 the hybrid approaches; the $\mathrm{R}^{2}$, training RMSE, testing RMSE, MAE, MAPE and IA are 0.839 and 0.881 , 3651.306 and $1.644,1.45$ and $1.184,1.161$ and $0.93,8.485$ and $6.852,0.952$ and 0.967 respectively. Moreover, 366 the ARIMA model performs worse than the other approaches. Both the EEMD-ANN and EEMD-SVM 367 have superior scores in predicting MTSF. The EEMD-ANN has gained a substantial $\mathrm{R}^{2}$, training RMSE, testing RMSE, MAE, MAPE, and IA of 0.923, 1.271, 1.124, 0.889, 6.133, and 0.971, respectively, which increases the $\mathrm{R}^{2}$ and IA by $10.012 \%$ and $1.995 \%$ and reduces the training RMSE by $2.68 \%$, testing RMSE by $22.482 \%$, MAE by $23.428 \%$ and MAPE by $2.352 \%$ compared to the conventional ANN. The EEMD-

371 SVM has also acquired a significant $\mathrm{R}^{2}$, training RMSE, testing RMSE, MAE, MAPE, and IA of 0.924, $3721.412,1.089,0.909,6.323$, and 0.973 , respectively, which improves the $\mathrm{R}^{2}$ and IA by $4.881 \%$ and $0.62 \%$ 373 and minimizes the training RMSE by $14.112 \%$, testing RMSE by $8.024 \%$, MAE by $2.258 \%$ and MAPE by $3740.529 \%$ while comparing with the conventional SVM.

375 Fig. (7a) exhibits the predicted outcomes of the testing dataset of the LTSF using ANN, SVM, EEMD376 ANN, EEMD-SVM, and ARIMA models. The hydrograph suggests that these models' predicted values, 377 except for the ARIMA model, agree well with the observations of LTSF. However, several points exhibit 378 a clear difference between the predicted and observed values. These differences often occur during the 379 month of abrupt changes of TSF (e.g., 2012, 2014-2016). The scatterplot (Fig. 7b) indicates that the least380 square fit for the EEMD-SVM prediction is closest to the perfect 45-degree fit, closely followed by the 381 EEMD-ANN, SVM, and ANN approaches. However, there is a massive difference between the perfect fit 382 and the least-square fit for the ARIMA model prediction.

383 EEMD-SVM approach has performed better than all the models (Table 4) in almost every validation 384 metrics, which is coherent with the scatterplot (Fig. 7b) and the Taylor diagram (Fig. 7c) results. It is the 385 best among the LTSF prediction models used in this study, gaining an impressive $\mathrm{R}^{2}$ of 0.0 .886 , training 
RMSE of 0.291 , testing RMSE of 0.398 , MAE of 0.325 , MAPE of 17.925, and IA of 0.966 . However, the EEMD-ANN has a better performance in acquiring the lower training RMSE (0.23) than EEMD-SVM, but it was not consistent in gaining better $\mathrm{R}^{2}$ value (0.864), testing RMSE (0.439), MAE (0.352), MAPE (21.929), and IA (0.956). The conventional ANN, SVM, and ARIMA models were remarkably inferior to the hybrid approaches predicting the LTSF. Compared to the traditional SVM, the EEMD-SVM raises the $\mathrm{R}^{2}$, IA and lessens the training RMSE, testing RMSE, MAE, MAPE by $4.03 \%, 1.90 \%$ and $10.39 \%, 14.83 \%$, $11.79 \%, 32.07 \%$, which is remarkable.

\subsection{Sensitivity assessment}

The sensitivity analysis result of the best HTSF prediction model, EEMD-ANN, is shown in Fig. (8a). The rankings of the three most sensitive parameters are TSD, IMF1, and IMF2. Apart from these, all the parameters positively contribute to achieving better performance during the TSF prediction of the highfrequency months. TT, CPRCP, CAPE, and PRCP also played a pivotal role in constructing the EEMDANN model, followed by CRR, IMF3, WS50, RH, ST, DP, and KI (Fig. 8a). A similar result is observed in the three most sensitive parameters (Fig. 8b) for the EEMD-SVM model while predicting MTSF. In analysis of the best LTSF prediction model, which is EEMD-SVM. TSD, IMF1, IMF3 are the top three sensitive parameters for predicting LTSF using the EEMD-SVM model. IMF2, CAPE, CPRCP, CRR, TT, PRCP also play a vital role in constructing the model for predicting LTSF. Although the parameters like DP, KI, RH, ST, and WS50 have low sensitivity value, they help achieve better prediction accuracy.

\section{Discussion and conclusion}

407 Due to increasing computational abilities, machine learning algorithms in modeling severe weather events are 408 becoming progressively popular in current atmospheric studies. It is because of robust prospects from its use in 409 operational prediction (McGovern et al., 2017; Czernecki et al., 2016; Kamangir et al., 2020) and the generating 410 of severe weather events that add forthcoming changes in their frequencies (Allen et al., 2015; Lee et al., 2020).

411 It is a fact that most current machine learning models have superiority over conventional statistical models 
412 (Gagne et al., 2017). Furthermore, some machine learning models like random forest permit studying variable

413 importance, making it likely to obtain a better insight into the factors influencing physics behind such studied

414 processes.

415 In this research, we assessed the use of machine learning algorithms in modeling high, moderate, and low 416 frequencies thunderstorm events on a monthly scale. This analysis was based on the observed TSF dataset, and 417 convective parameters come from ERA5 reanalysis datasets. In the case of HTSF, the hybrid EEMD-ANN 418 outperformed other models based on the evaluation criteria. For MTSF and LTSF, the hybrid EEMD-SVM 419 model has superior performance than other standalone models. Theoretically, the three sub-series with various thunderstorm frequencies were used instead of thunderstorm events because it has physical meaning. TSF analysis can be used operationally to help human policy-making by lessening the cognitive associated with thunderstorm event identification.

423 Uncertainty increases in low TSF months (winter) because of the low SST and northeast wind flow from the $424 \mathrm{BoB}$ and lowers vapor flux availability. We anticipate that due to low surface temperature and soil moisture, the 425 winter season (November to February) is the least favorable for forming TSF. However, this outcome is not 426 surprising, and it can be underlined by analyzing the TSF pattern of three categories. This work proposed a 427 prediction strategy for TSF prediction circumventing the probable precision reduction triggering from calibrating 428 the decomposition method during implementing and accepting the application of operational research reported 429 in several previous works (Napolitano et al., 2011; Zhang et al., 2015; Johny et al., 2020).

430 The outcomes obtained in this research indicate that EEMD can efficiently increase prediction accuracy, and the proposed EEMD-ANN model can achieve notable improvement over the conventional ANN method in the high,

432 medium, and low TSF monthly time-series predictions. The EEMD-ANN is more successful in capturing the 433 HTSF monthly, showing remarkable precision than the SVM-EEMD model. Our finding is similar to the other 434 hydrological time-series studies (Wang et al., 2015). One probable reason for the improved performance of 435 EEMD-ANN can be the method's capability to solve complex and nonlinear problems (Phuong et al., 2017).

436 In predicting MTSF, the Taylor diagram suggests EEMD-ANN is slightly more accurate than the EEMD-SVM.

437 But the validation metrics suggest otherwise. We have selected the EEMD-SVM as the best model for MTSF 438 prediction because the difference between the models is very narrow in the Taylor diagram, and it has performed 
better in most of the validation metrics. Besides, the EEMD-SVM has gained a substantial improvement in testing RMSE than EEMD-ANN, which indicates better model fitting for EEMD-SVM. The difference in the Taylor diagram and validation metrics results is probably due to the diagram's algorithm based on root mean square difference, standard deviation, and correlation coefficient. The standard deviation of the observed and predicted datasets might create this result difference. Also, the EEMD-SVM is more accurate in predicting the LTSF monthly. This is because SVM has been incredibly robust and efficient in nonlinear noise mixed data (Devak et al., 2015). Besides, the potential of decomposition might be more prominent in predicting the TSF dataset in the EEMD-ANN or EEMD-SVM model than the standalone model because the hybrid model can overcome the shortcomings of the standalone model to produce a synergetic impact on prediction. The hybrid EEMD-SVM can help avoid the overfitting or underfitting problem of the SVM model caused by the input parameters' improper determination. This also implies that the EEMD tool is applicable for decomposing monthly TSF time series and the idea of "decomposition and ensemble" is suitable. The findings in this work agree well with those obtained from the studies (Hawinkel et al., 2015; Wang et al., 2015; Czernecki et al., 2016). Previous studies have found that hybrid EEMD-ANN and EEMD-SVM models outperformed the classical models, which apply original datasets in other fields of studies, e.g., runoff (Tan et al., 2018); streamflow forecasting (Zhang et al. 2015); rainfall forecasting (Johny et al. 2020) wind speed forecasting (Yu, 2020); groundwater level (Gong et al., 2018). The hybrid model is robust, theoretically justified, and more realistic compared to other standalone models. It can be said that the proposed methodology can not only predict the complicated thunderstorm frequency over Bangladesh rationally well, but it can also attain extreme climatic events.

459 Topographical differences, wind regimes, and the inland distance far from the coastal and hilly regions may 460 differ sensitivity results in these categories. Based on the sensitivity assessment, TSD, IMF1, and IMF2 461 generated the highest score, similar to other thunderstorm-associated parameters in India by Umakanth et al. 462 (2020). TSD is very high in sensitivity analysis due to an enhanced number of TSF causing moist air circulated 463 from the Bay of Bengal (BoB). When passing the equatorial belt, the southeastern air masses go into the 464 southwest monsoon due to Ferrell's law, which brings a large amount of thunderstorm in the country. Generally, the high TSD in May and June is observed in the northeast region, close to Cherapunji, where the cloud formation 
is high, and hill ranges generate a tremendous amount of water vapor flex and precipitation. In recent times,

467 more vigorous and more continuous moist is derived from the $\mathrm{BoB}$ because of elevated sea surface temperature.

468 The high sea surface temperature triggered a rise in CAPE in most parts of Bangladesh (Wahiduzzaman et al.,

469 2020; Sahu et al., 2020). These findings support the outcomes of Glazer et al. (2020), who assessed the variations

470 in TSD in Bangladesh due to global climate change and revealed an increase in TSD in many regions of the

471 country. An increase in CAPE and higher moisture content in the BoB may play a vital role in enhancing TSD.

472 Thus, the sensitivity assessment gives a physical means to capture the non-overlapping TSD that would

473 otherwise trigger the concern of multicollinearity. This is obvious from the improvement in the model

474 performance for high TSF identification reported in earlier works (Siddiqui and Rashid, 2008; Gagne et al.,

475 2017). Generally, the problem of over-prediction is a familiar matter for predicting a severe extreme event that

476 can be lessened using current machine learning methods (Czernecki et al., 2019), particularly if various data

477 sources are coupled. All the other convective parameters, e.g., TT, CPRCP, CRR, KI, and the meteorological

478 parameters, e.g., PRCP, RH, ST, WS50, have positively contributed to the best model building. This is because

479 all these input parameters are positively associated with a high correlation with thunderstorm occurrences.

480 Employing these hybrid ensemble models to predict monthly TSF is crucial for further studies. There are some 481 advantages to the proposed hybrid models. First, the basic principle of the EEMD is elementary, can still give a 482 thorough understanding of the monthly TSF time series dataset. Second, it is suitable and adequate to couple the EEMD with ANN, ARIMA, SVM to predict the nonstationary and nonlinear TSF. Third, the EEMD-ANN and EEMD-SVM models' prediction outcomes are more precise when applying the TSF time series decomposition.

485 Fourth, the developed hybrid models do not need complex policy-making about each specific case study's 486 obvious form. Thus, developing these hybrid prediction models by integrating EEMD may lead to more robust 487 and better prediction outcomes. It may also be useful in further studies focused on extreme events prediction for 488 various problems related to effective disaster management. The application of machine learning algorithms in a 489 thunderstorm prediction brings with a new promise for forthcoming studies concerning both operational 490 predictors and meteorological research that intend to examine observed and future variations in frequencies of severe extreme events (Yasen et al., 2017; Taszarek et al., 2019). 
It is worth mentioning that the limitation of this research lies in two perspectives. First, although monthly TSF data were taken from 28 stations, future studies using datasets from different regions may be needed to strengthen these valid conclusions because the performance of data-driven models is data-based and case reports explicit. Second, the coupling preprocessing technique with a machine learning algorithm, a division of the training and testing datasets, and model selection criteria are a vital factor affecting the overall performance of the hybrid models. Thus, future works are solicited, which may shed much light on this concern. Our future work includes the case-study concept of generating a seasonal TSF forecasting on a continental scale that can provide deep insight into the severe weather event's current knowledge. Also, testing our hybrid model is to forecast thunderstorm frequency for other similar climatic regions globally. The ERA5 based parameters can be used in the RF model that is yet more reliable than any sole parameters used in operational models (Gagne et al., 2017). In addition to this, good tuning of generated machine learning is feasible if it is more robustly fitted on a considerable number of datasets or adding new parameters from satellite datasets. Hence, with computational interests in modeling tools, machine learning models play a pivotal role in examining thunderstorm events'

505 climatological perspective and improving operational prediction.

\section{Acknowledgement}

507 We are grateful to the Department of Disaster Management, Begum Rokeya University, Rangpur for all 508 sort of assistant provided during this study. Furthermore, we would like to thank the Bangladesh 509 Meteorological Department (BMD) for providing required data for this research.

\section{Conflict of interest}

511 None

512 References

513 Ahmed, M.K., Alam, M.S., Yousuf, A.H.M., Islam, M.M., 2017. A long-term trend in precipitation of different 514 spatial regions of Bangladesh and its teleconnections with El Nino/ southern oscillation and Indian Ocean dipole. 515 Theor. Appl. Climatol. 129 (1-2), 473-486. https://doi.org/10.1007/s00704-016-1765-2

516 Ali, A.F., Johari, D., Ismail, N.F.N., Musirin, I., Hashim, N., 2011. Thunderstorm forecasting by using artificial 517 neural network. 5th International Power Engineering and Optimization Conference, Shah Alam, Selangor, 2011, 518 pp. 369-374. https://10.1109/PEOCO.2011.5970391 
Alizadeh, M., Alizadeh, E., Asadollahpour Kotenaee, S., Shahabi, H., Beiranvand Pour, A., Panahi,M., et al., 2018. Social vulnerability assessment using artificial neural network (ANN) model for earthquake hazard in Tabriz city, Iran. Sustainability. 10, 3376. https://doi.org/10.3390/su10103376

Allen, J.T., Karoly, D.J., 2014. A climatology of Australian severe thunderstorm environments 1979-2011: interannual variability and ENSO influence. Int. J Climatol. 34, 81-97. https://doi.org/10.1002/joc.3667

524 Allen, J.T., Tippett, M.K., Sobel, A.H., 2015. An empirical model relating US monthly hail occurrence to large-

525 scale meteorological environment. J. Adv. Model. Earth Syst. 7, 226-243. 526 https://doi.org/10.1002/2014MS000397.

527 Boateng, E.B., Pillay, M., Davis, P., 2019. Predicting the level of safety performance using an artificial neural network. In: Ahram, T., Karwowski, W., Taiar, R. (Eds.), Human Systems Engineering and Design. Advances in Intelligent Systems and Computing. 876, 705-710. https://doi.org/10.1007/978-3-030-02053-8 107 Boussabaine, A.H., 1996. The use of artificial neural networks in construction management: a review. Constr. Manag. Econ. 14 (5), 427-436. https://doi.org/10.1080/014461996373296

532 Bouttier, F., Marchal, H., 2020. Probabilistic thunderstorm forecasting by blending multiple ensembles. Tellus 533 A: Dynamic Meteorology and Oceanography. 72(1), 1-19. https://doi.org/10.1080/16000870.2019.1696142

534 Box, G., Jenkins, G., 1970. Time series analysis: forecasting and control. Wiley, Hoboken.

535 Carrier, C., Kalra, A., Ahmad, S., 2013. Using paleo reconstructions to improve streamflow forecast lead time 536 in the western United States. J.A.W.R.A. J. Am. Water Resour. Assoc. 49 (6), 1351-1366. 537 https://doi.org/10.1111/jawr.12088

538 Ch, S., Anand, N., Panigrahi, B.K., Mathur, S., 2013. Streamflow forecasting by SVM with quantum behaved 539 particle swarm optimization. Neurocomputing. 101, 18-23. https://doi.org/10.1016/j.neucom.2012.07.017

540 Chen, I., Hong, J., Tsai, Y., Fong, C., 2020. Improving Afternoon Thunderstorm Prediction over Taiwan through 541 3DVar-Based Radar and Surface Data Assimilation. Weather and Forecasting. 35(6), 2603-2620. 542 https://doi.org/10.1175/WAF-D-20-0037.1

543 Chen, L., Letchford, C.W., 2007. Numerical simulation of extreme winds from thunderstorm downbursts. 544 Journal of Wind Engineering and Industrial Aerodynamics. $95 \quad$ (9-11), 977-990. $545 \quad$ https://doi.org/10.1016/j.jweia.2007.01.021 
547 speed predicting framework based on EEMD-GA-LSTM method under large scaled wind history. Energy

548 Conversion and Management. 227, 113559. https://doi.org/10.1016/j.enconman.2020.113559

549 Chiogna, G., Marcolini, G., Liu, W., Pérez Ciria, T., Tuo, Y., 2018. Coupling hydrological modeling and support

550 vector regression to model hydropeaking in alpine catchments. Science of The Total Environment. 633, 220-

551 229. https://10.1016/j.scitotenv.2018.03.162

552 Collins, W., Tissot, P., 2015. An artificial neural network model to predict thunderstorms within $400 \mathrm{~km}^{2} \mathrm{South}$

553 Texas domains. Meteorol. Appl. 22, 650-665. https://10.1002/met.1499

554 Contreras, J., Espinola, R., Nogales, F.J., Conejo, A.J., 2003. A.R.I.M.A. models to predict next-day electricity 555 prices. IEEE Transactions on Power Systems. 18(3), 1014-1020. https://10.1109/TPWRS.2002.804943

556 Czernecki, B., Taszarek, M., Kolendowicz, L., Konarski, J., 2016. Relationship between human observations of 557 thunderstorms and the PERUN lightning detection network in Poland. Atmos. Res. 167, 118-128. $558 \quad$ https://doi.org/10.1016/j.atmosres.2015.08.003.

559 Devak, M., Dhanya, C., Gosain, A., 2015. Dynamic coupling of support vector machine and K-nearest neighbour 560 for downscaling daily rainfall. Journal of Hydrology, 525: 286-301. 561 https://doi.org/10.1016/j.jhydrol.2015.03.051

562 Dowdy, A.J., 2016. Seasonal forecasting of lightning and thunderstorm activity in tropical and temperate regions 563 of the world. Sci. Rep. 6, 20874. https://doi.org/10.1038/srep20874

564 Fan, X., Zhang, Y., Krehbiel, P.R., Zhang, Y., Zheng, D., Yao, W., Xu, L., Liu, H., Lyu, W., 2020. Application 565 of ensemble empirical mode decomposition in low-frequency lightning electric field signal analysis and 566 lightning location. IEEE Trans. Geosci. Remote Sens. 59, 86-100. https://doi.org/10.1109/TGRS.2020.2991724

567 Gagne, D.J., McGovern, A., Haupt, S.E., Sobash, R.A., Williams, J.K., Xue, M., 2017. Storm-based probabilistic 568 hail forecasting with machine learning applied to convection-allowing ensembles. Weather Forecast. 32, 1819569 1840. https://doi.org/10. 1175/WAF-D-17-0010.1

570 Gao, J., Stensrud, D.J., 2014. Some Observing System Simulation Experiments with a Hybrid 3DEnVAR System 571 for Storm-Scale Radar Data Assimilation. Monthly Weather Review. 142(9), 3326-3346. 572 https://doi.org/10.1175/MWR-D-14-00025.1 
573 Ghimire, S., Deo, R. C., Downs, N. J., Raj, N., 2019. Global solar radiation prediction by ANN integrated with

574 European Centre for medium range weather forecast fields in solar rich cites of Queensland Australia. Journal

575 of Cleaner Production. 216, 288-310. https://10.1016/j.jclepro.2019.01.158

576 Glazer, R.; Torres-Alavez, J.A.; Coppola, E.; Das, S.; Ashfaq, M.; Sines, T. Projected changes to Severe

577 Thunderstorm environments as a result of 21st century warming from RegCM CORDEX-CORE simulations.

578 EGU Gen. Assem. 2020, 2020, 970

579 Gong, Y., Wang, Z., Xu, G., Zhang, Z., 2018. A Comparative Study of Groundwater Level Forecasting Using

580 Data-Driven Models Based on Ensemble Empirical Mode Decomposition, Water 2018, 10, 730;

581 doi:10.3390/w10060730

582 Haklander, A.J., Delden, A.V., 2003. Thunderstorm predictors and their forecast skill for the Netherlands.

583 Atmospheric Research. 67-68, 273-299. https://doi.org/10.1016/S0169-8095(03)00056-5

584 Hawinkel, P.; Swinnen, E.; Lhermitte, S.; Verbist, B.; Van Orshoven, J.; Muys, B., 2015. A time series

585 processing tool to extract climate-driven interannual vegetation dynamics using ensemble empirical mode

586 decomposition (EEMD). Remote Sens. Environ. 169, 375-389

587 Huang, N.E., Zheng S., Steven R. L., Manli C.W., Hsing H.S., Quanan Z., Nai-Chyuan Y., Chi C.T., Henry H.

588 L., 1998. The Empirical Mode Decomposition and the Hilbert Spectrum for Nonlinear and Non-Stationary Time

589 Series Analysis. Proceedings: Mathematical, Physical and Engineering Sciences 454, no. 1971, 903-95.

590 https://www.jstor.org/stable/53161

591 Huang, S., Chang, J., Huang, Q., Chen, Y., 2014. Monthly streamflow prediction using modified EMD-based

592 support vector machine. Journal of Hydrology. 511, 764-775. https://doi.org/10.1016/j.jhydrol.2014.01.062

593 Islam, A.R.M.T., Nafiuzzaman, M., Rifat, J., Rahman, M.A., Chu, R., Li, M., 2020. Spatiotemporal variations

594 of thunderstorm frequency and its prediction over Bangladesh. Meteorol. Atmos. Phys.

595 https://doi.org/10.1007/s00703-019-00720-6

596 Jacovides, C.P., Yonetani, T., 1990. An evaluation of stability indices for thunderstorm prediction in greater

597 Cyprus. American Meteorological Society. 5 (4), 559-569. $\underline{\text { https://doi.org/10.1175/1520- }}$

$598 \quad \underline{0434(1990) 005<0559: A E O S I F>2.0 . C O ; 2}$ 

forecasting, Theoretical and Applied Climatology https://doi.org/10.1007/s00704-020-03177-5 Kamangir, H, Collins, W., Tissot P, King, S.A., 2020. A deep-learning model to predict thunderstorms within 400 km2 South Texas domains, Meteorological Application, https://doi.org/10.1002/met.1905 Karlaftis, M.G., Vlahogianni, E.I., 2011. Statistical methods versus neural networks in transportation research: differences, similarities and some insights. Transport. Res. C Emerg. Technol. 19 (3), 387-399. https://doi.org/10.1016/j.trc.2010.10.004

Kulikov, M.Y., Belikovich, M.V., Skalyga, N.K., Shatalina, M.V., Dementyeva, S.O., Ryskin, V.G., Shvetsov, A.A., Krasil'nikov, A.A., Serov, E.A., Feigin, A.M., 2020. Skills of Thunderstorm Prediction by Convective Indices over a Metropolitan Area: Comparison of Microwave and Radiosonde Data. Remote Sens. 12, 604. https://doi.org/10.3390/rs12040604 Development Thunderstorm (RDT) Algorithm for Use with the GK2A Satellite, Asia-Pacific Journal of

612 Atmospheric Sciences https://doi.org/10.1007/s13143-020-00182-6

613 Litta, A.J., Idicula, S.M., Mohanty, U.C., 2013. Artificial Neural Network model in prediction of meteorological 614 parameters during premonsoon thunderstorms. International Journal of Atmospheric Sciences. 2013, 14. 615 https://doi.org/10.1155/2013/525383

616 Liu, Y., Wang, R., 2016. Study on network traffic forecast model of S.V.R. optimized by G.A.F.S.A. Chaos, 617 Solitons \& Fractals 89, 153-159. https://doi.org/10.1016/j.chaos.2015.10.019

618 Mannan, M.A., Chowdhury, M.A.M., Karmakar, S., Ahmed, S., Rahman, A., Mondal, M.S.H., 2016. Prediction 619 of heavy rainfall in association with severe thunderstorm in Bangladesh during pre-monsoon season. The 620 Atmosphere, Bangladesh Meteorological Department, Dhaka, Bangladesh. 6(1), 64-76.

621 Manzato, A., 2007. Sounding-derived indices for neural network based short-term thunderstorm and rainfall 622 forecasts. Atmospheric Research. 83, 349-365. https://10.1016/j.atmosres.2005.10.021

623 McGovern, A., Elmore, K.L., Gagne, D.J., Haupt, S.E., Karstens, C.D., Lagerquist, R., Smith, T., Williams, J.K., 624 2017. Using artificial intelligence to improve real-time decision-making for high-impact weather. Bull. Am. 625 Meteorol. Soc. 98, 2073-2090. https://doi.org/10.1175/BAMS-D-16-0123.1. 
626 Meher, J.M., Das, L., 2019. Skill of CMIP5 climate models to reproduce the stability indices in identifying

627 thunderstorms over the Gangetic West Bengal. Atmospheric Research. 225, 172-180.

628 https://doi.org/10.1016/j.atmosres.2019.04.006

629 Meng, E., Huang, S., Huang, Q., Fang, W., Wu, L., Wang, L., 2019. A robust method for non-stationary

630 streamflow prediction based on improved EMD-SVM model. Journal of Hydrology. 568, 462-478.

631 https://doi.org/10.1016/j.jhydrol.2018.11.015

632 Mills, G.A., Colquhoun, J.R., 1998. Objective prediction of severe thunderstorm environments: Preliminary

633 results linking a decision tree with an operational regional N.W.P. model. Weather and Forecasting. 13, 1078-

634 1092. https://doi.org/10.1175/1520-0434(1998)013<1078:OPOSTE >2.0.CO;2

635 Napolitano G, Serinaldi F, See L., 2011. Impact of EMD decomposition and random initialisation of weights in

636 ANN hindcasting of daily stream flow series: an empirical examination. J Hydrol 406:199-214

637 Osuri, K.K., Nadimpalli, R., Mohanty, U.C., Chen, U., Rajeevan, M., Niyogi, D., 2017. Improved prediction of

638 severe thunderstorms over the Indian Monsoon region using high-resolution soil moisture and temperature

639 initialization. Sci. Rep. 7, 41377. https://doi.org/10.1038/srep4 1377

640 Pakalidou, N., Karacosta, P., 2018. Study of very long-period extreme precipitation records in Thessaloniki,

641 Greece. Atmospheric Research. 208, 106-115. https://doi.org/10.1016/j.atmosres.2017.07.029

642 Pham, B.T., Nguyen, M.D., Dao, D.V. et al., 2019. Development of artificial intelligence models for the 643 prediction of Compression Coefficient of soil: An application of Monte Carlo sensitivity analysis. Sci. Total 644 Environ. 679, 172-184. https://doi.org/10.1016/j.scitotenv.2019.05.061

645 Phuong, N.T.B., Duy, N.B., Nghiem, N.C., 2017. Remote sensing for monitoring surface water quality in the 646 Vietnamese Mekong delta: the application for estimating chemical oxygen demand in river reaches in Binh Dai, 647 Ben Tre. Vietnam Journal of Earth Sciences 39, 256-268. https://doi.org/10.15625/0866-7187/39/3/10270

648 Pradhan, B., Lee, S., 2010. Landslide susceptibility assessment and factor effect analysis: backpropagation 649 artificial neural networks and their comparison with frequency ratio and bivariate logistic regression modelling.

650 Environ. Model Softw. 25, 747-759. https://doi.org/10.1016/j.envsoft.2009.10.016 
651 Qiu, G., Wu, Z., Li, Z., Du, Q., 2010. Application of least square support vector machine for thunderstorm

652 prediction. 8th World Congress on Intelligent Control and Automation, Jinan, 2010, pp. 345-349, 653 https://10.1109/WCICA.2010.5555057

654 Rädler, A.T., Groenemeijer, P.H., Faust, E., Sausen, R., Púčik, T., 2019. Frequency of severe thunderstorms 655 across Europe expected to increase in the 21 st century due to rising instability. Clim. Atmos. Sci. 2, 30. 656 https://doi.org/10.1038/s41612-019-0083-7

657 Rahman, M.S., Azad, M.A.K., Hasanuzzaman, M., Salam, R., Islam, A.R.M.T., Rahman, M.M., Hoque, 658 M.M.M., 2020. How air quality and COVID-19 transmission change under different lockdown scenarios? A 659 case from Dhaka city, Bangladesh. Sci. Total Environ. 143161. https://doi.org/10.1016/j.scitotenv.2020.143161 660 Rahman, M.S., Islam, A.R.M.T., 2019. Are precipitation concentration and intensity changing in Bangladesh 661 overtimes? Analysis of the possible causes of changes in precipitation systems. Sci. Total Environ. 690, 370387. https://doi.org/10.1016/j.scitotenv.2019.06.529

663 Saha, T.R., Quadir, D.A., 2016. Variability and trends of annual and seasonal thunderstorm frequency over 664 Bangladesh. Inter. J. Climatol. 36, 4651-4666. https://10.1002/joc.4663

665 Sahu, R.K.; Dadich, J.; Tyagi, B.; Visa, N.K.; Singh, J., 2020. Evaluating the impact of climate change in 666 threshold valuesofthermodynamicindicesduringpre-monsoonthunderstormseasonoverEasternIndia. Nat. 667 Hazards, 102, 1541-1569

668 Salam, R., Islam, A.R.M.T., 2020. Potential of R.T., Bagging and R.S. ensemble learning algorithms for 669 reference evapotranspiration prediction using climatic data-limited humid region in Bangladesh. J. Hydrol. 590, 670 125241. https://doi.org/10.1016/j.jhydrol.2020.125241

671 Shadab, A., Ahmad, S., Said, S., 2020. Spatial forecasting of solar radiation using A.R.I.M.A. model. Remote 672 Sensing Applications: Society and Environment. 20, 100427. https://doi.org/10.1016/j.rsase.2020.100427

673 Siddiqui, Z.A., Rashid, A., 2008. Thunderstorm frequency over Pakistan. Pak. J. Meteorol. 5, 39-63.

674 Solari, G., Rainisio, D. De Gaetano, P., 2017. Hybrid simulation of thunderstorm outflows and wind-excited 675 response of structures. Meccanica. 52, 3197-3220. https://doi.org/10.1007/s11012-017-0718-X 
676 Suparta, W., Putro, W.S., 2018. Parametric studies of A.N.F.I.S. family capability for thunderstorm prediction.

677 Space Science and Communication for Sustainability. Springer, Singapore. https://doi.org/10.1007/978-981-10-

$678 \quad \underline{6574-3 \quad 2}$

679 Tan QF, Lei XH, Wang X et al., 2018. An adaptive middle and long-term runoff forecast model using EEMD-

680 ANN hybrid approach. J Hydrol 567:767-780

681 Taszarek, M., Allen, J., Púčik, T., Groenemeijer, P., Czernecki, B., Kolendowicz, L., Lagouvardos, K., Kotroni,

682 V., Schulz, W., 2019. A climatology of thunderstorms across Europe from a synthesis of multiple data sources.

683 J. Clim. 32 (6), 1813-1837. https://doi.org/10.1175/JCLI-D-18-0372.1.

684 Taylor, K.E., 2001. Summarizing multiple aspects of model performance in a single diagram. J. Geophys. Res.

685 106, 7183-7192. https://doi.org/10.1029/2000JD900719

686 Trenberth, K.E., Jones, P.D., Ambenje, P. et al., 2007. Observations: Surface and atmospheric climate change.

687 Chapter 3 in S. Solomon, D. Qin, M. Manning, Z. Chen, M. Marquis, K.B. Averyt, M. Tignor and H.L. Miller

688 (eds.), Climate Change 2007: The Physical Science Basis. Contribution of Working Group I to the Fourth

689 Assessment Report of the Intergovernmental Panel on Climate Change. Cambridge University Press, Cambridge,

690 United Kingdom and New York, NY, U.S.A.

691 Vapnik, V., 1995. The Nature of Statistical Learning Theory. Springer Verlag, New York, U.S.A.

692 https://doi.org/10.1007/978-1-4757-3264-1

693 Vapnik, V., 1998. Statistical learning theory, 1. Wiley, New York.

694 Vujović, D., Paskota, M., Todorović, N., Vučković, V., 2015. Evaluation of the stability indices for the

695 thunderstorm forecasting in the region of Belgrade, Serbia. Atmospheric Research, 161-162, 143-152.

696 https://doi.org/10.1016/j.atmosres.2015.04.005

697 Wahiduzzaman, M., Islam, A.R.M.T., Luo, J., Shahid S, Uddin, M.J., Shimul, S.M., Sattar, M.A., 2020. Trends

698 and Variabilities of Thunderstorm Days over Bangladesh on the ENSO and IOD Timescales. Atmosphere. 11,

699 1176. https://doi.org/10.3390/atmos11111176

700 Wang WC, Chau KW, Xu DM, Chen X.Y., 2015. Improving forecasting accuracy of annual runoff time series

701 using ARIMA based on EEMD decomposition. Wat Resour Manage 29:2655-2675 

of oceanic internal wave from synthetic aperture radar image. Journal of Shanghai Jiaotong University (Science). 20(2), 243-250. https://10.1007/s12204-015-1614-y

705 Wu, Z., Huang, N.E., 2009. Ensemble empirical mode decomposition: a noise-assisted data analysis method. 706 Advances in Adaptive Data Analysis 1, 1-41. https://doi.org/10.1142/S1793536909000047

707 Yasen, M., Al-Jundi, R., Al-Madi, N., 2017. Optimized ANN-ABC for Thunderstorms Prediction, IEEE, 98708 103, DOI: 10.1109/ICTCS.2017.37

709 Umakanth, N., Satyanarayana, G.C., Simon, B., Rao, M.C., Babu, N.R., 2020. Long-term analysis 710 of thunderstorm-related parameters over Visakhapatnam and Machilipatnam, India, Acta Geophysica 711 https://doi.org/10.1007/s11600-020-00431-2

712 Yu, M., 2020. Short-term wind speed forecasting based on random forest model combining ensemble empirical 713 mode decomposition and improved harmony search algorithm, International Journal of Green Energy, 17:5, 332-

714 348, DOI: $10.1080 / 15435075.2020 .1731816$

715 Zhang X, Peng Y, Zhang C, Wang, B., 2015. Are hybrid models integrated with data pre-processing techniques 716 suitable for monthly streamflow forecasting? Some experiment evidences. J Hydrol 530:137-152

717 Zhen-hui, W., Yi, Z., Jia, Z., 2013. A preliminary study on thunderstorm forecast with LS-SVM method. Journal 718 of Tropical Meteorology. 19(1), 104-108.

719 Zhou, Q., Jiang, H., Wang, J., Zhou, J., 2014. A hybrid model for PM 2.5 forecasting based on ensemble 720 empirical mode decomposition and a general regression neural network. Science of The Total Environment. 496, 721 264-274. https://doi.org/10.1016/j.scitotenv.2014.07.051 


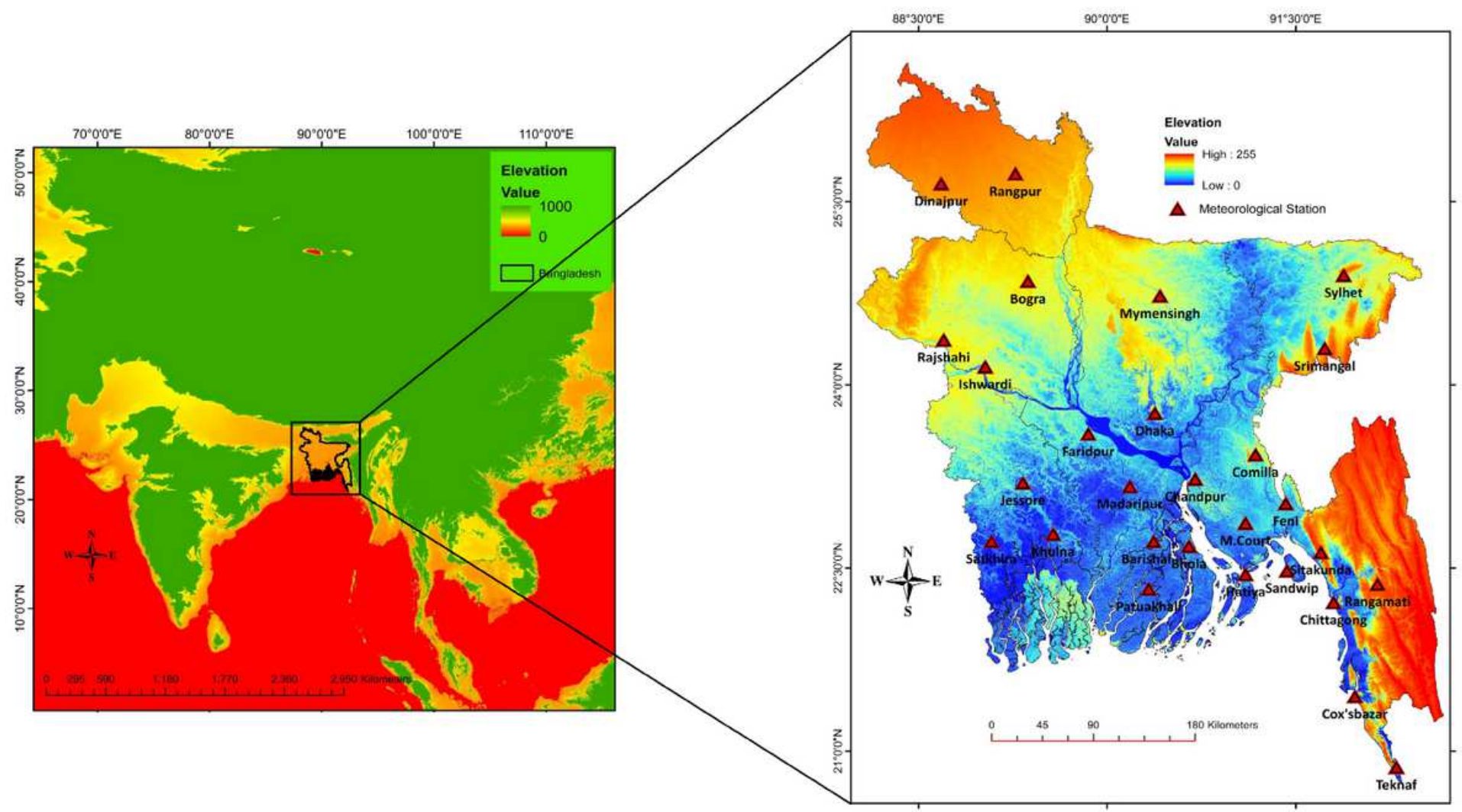

\section{Figure 1}

Geographical location of the study area, red delta signs represent the selected meteorological stations of BMD. Note: The designations employed and the presentation of the material on this map do not imply the expression of any opinion whatsoever on the part of Research Square concerning the legal status of any country, territory, city or area or of its authorities, or concerning the delimitation of its frontiers or boundaries. This map has been provided by the authors. 


\section{Input Layer}

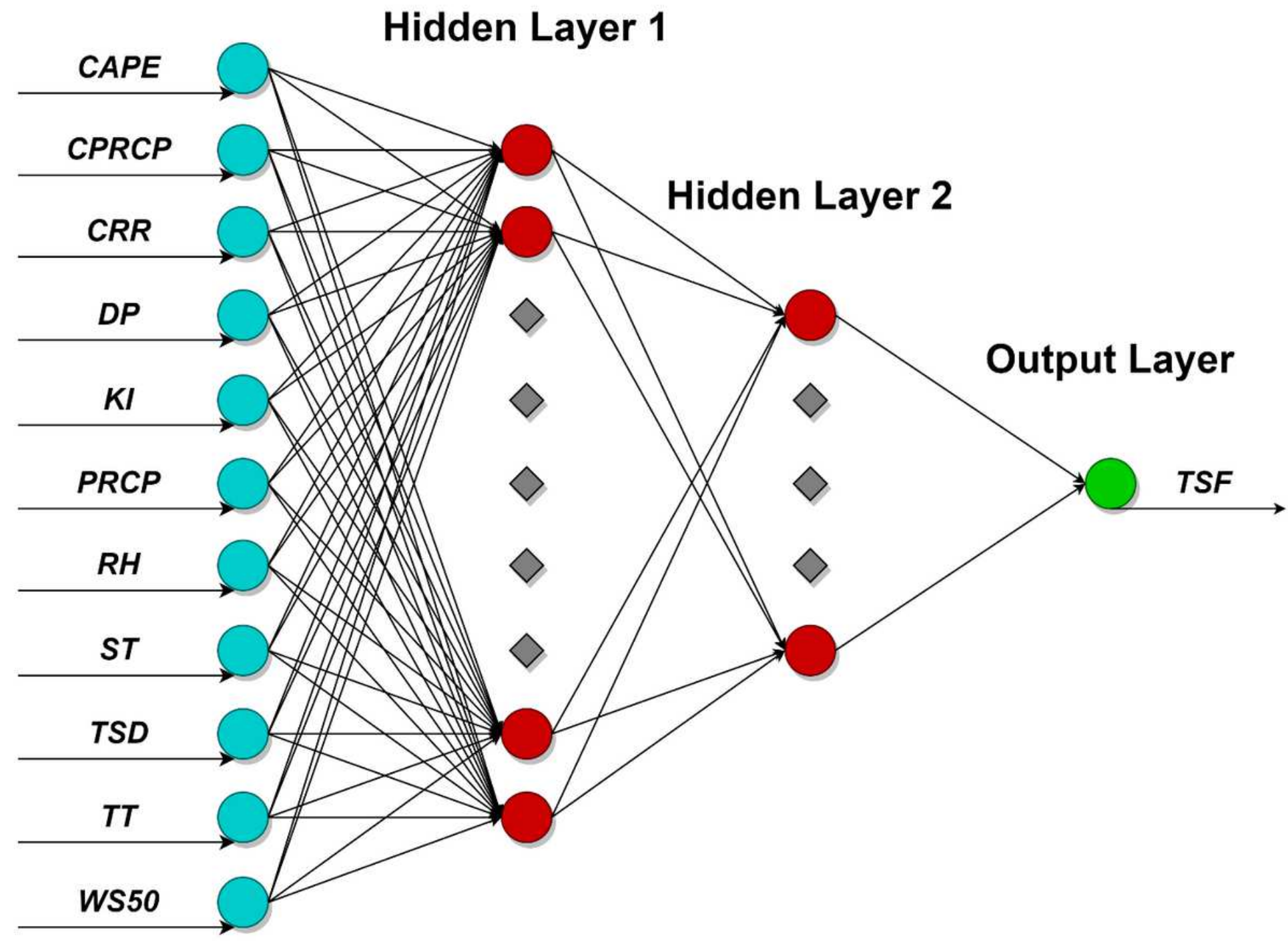

Figure 2

Architecture of the artificial neural network (ANN) model with an input layer, two hidden layers, and an output layer used for predicting monthly thunderstorm frequency. 


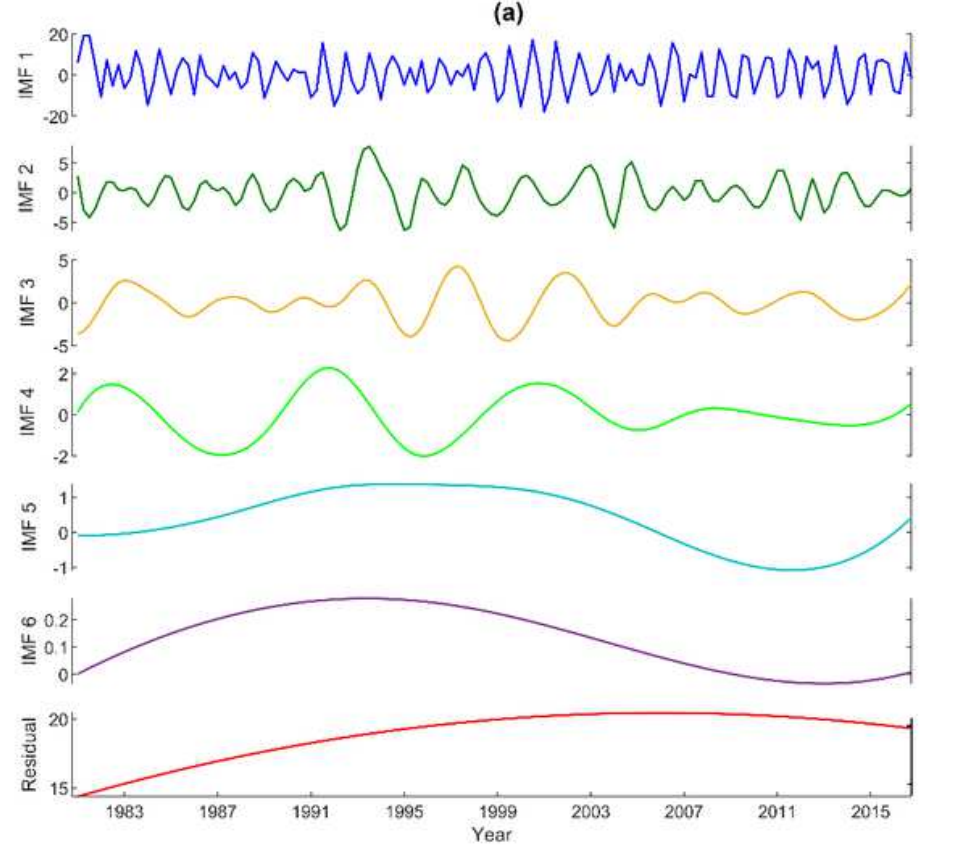

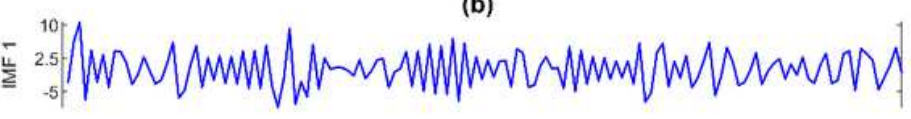
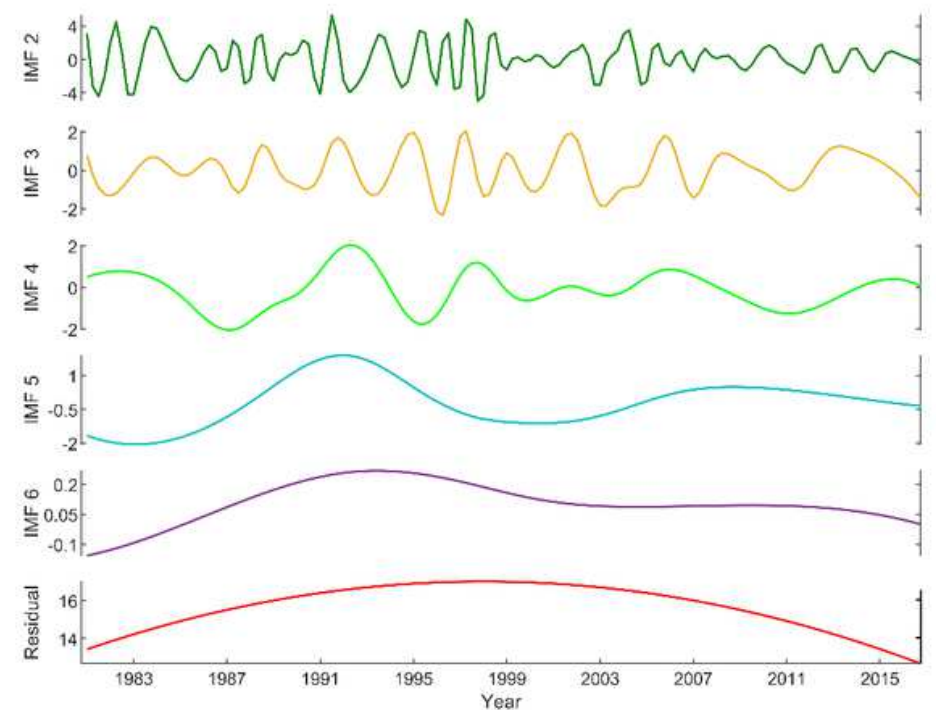

(c)

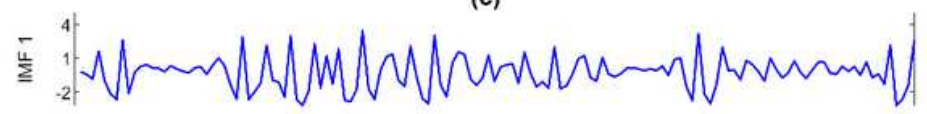

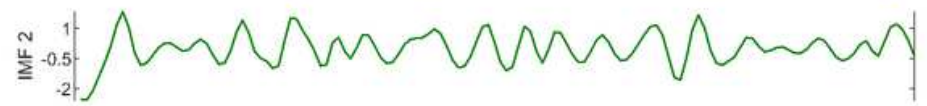
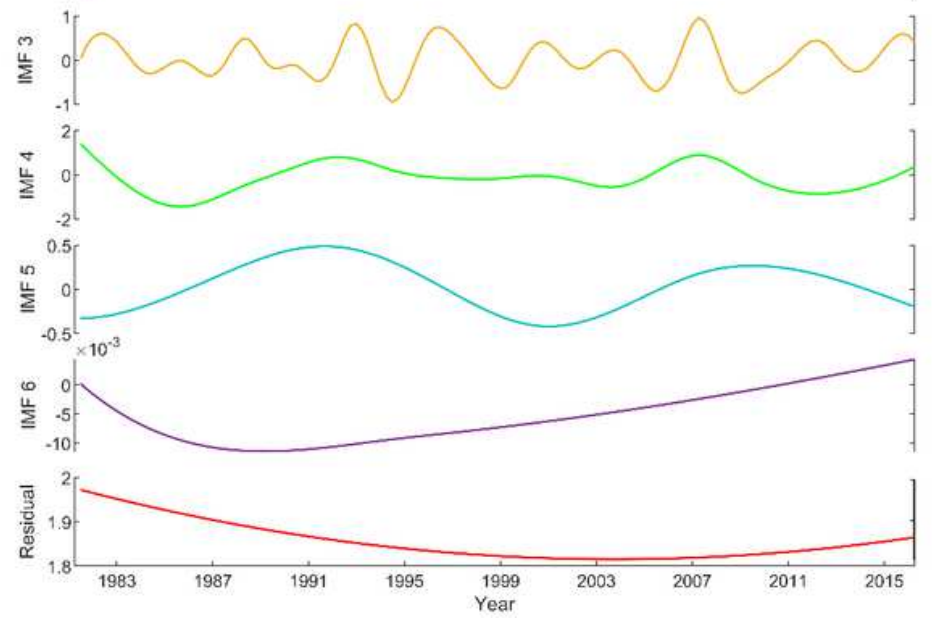

Figure 3

The decomposed sub-series of the original TSF data for high-frequency months (a), moderate-frequency months (b), and low-frequency months series (c) using EEMD. 


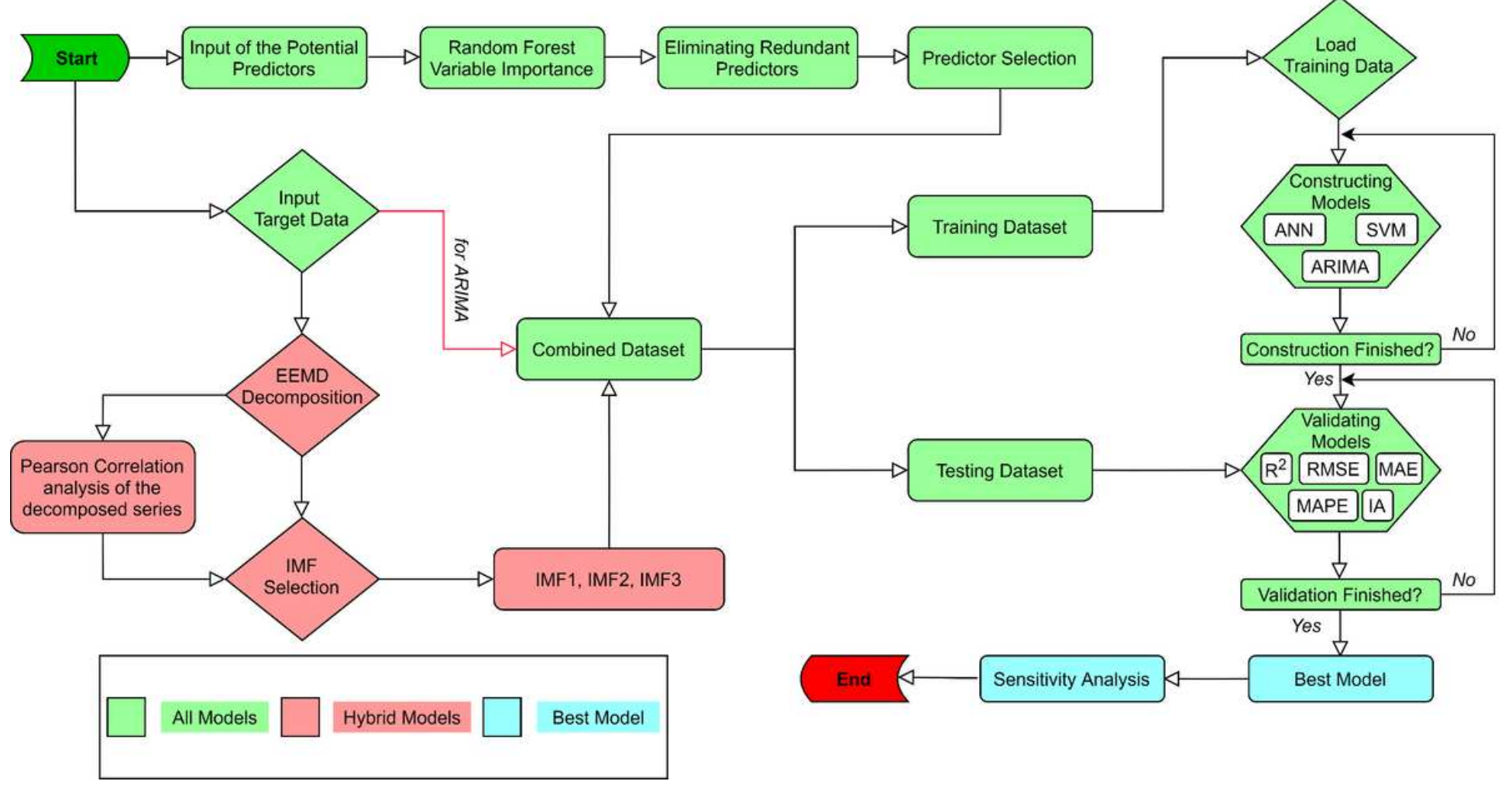

Figure 4

Flow diagram of the methodological processes. 

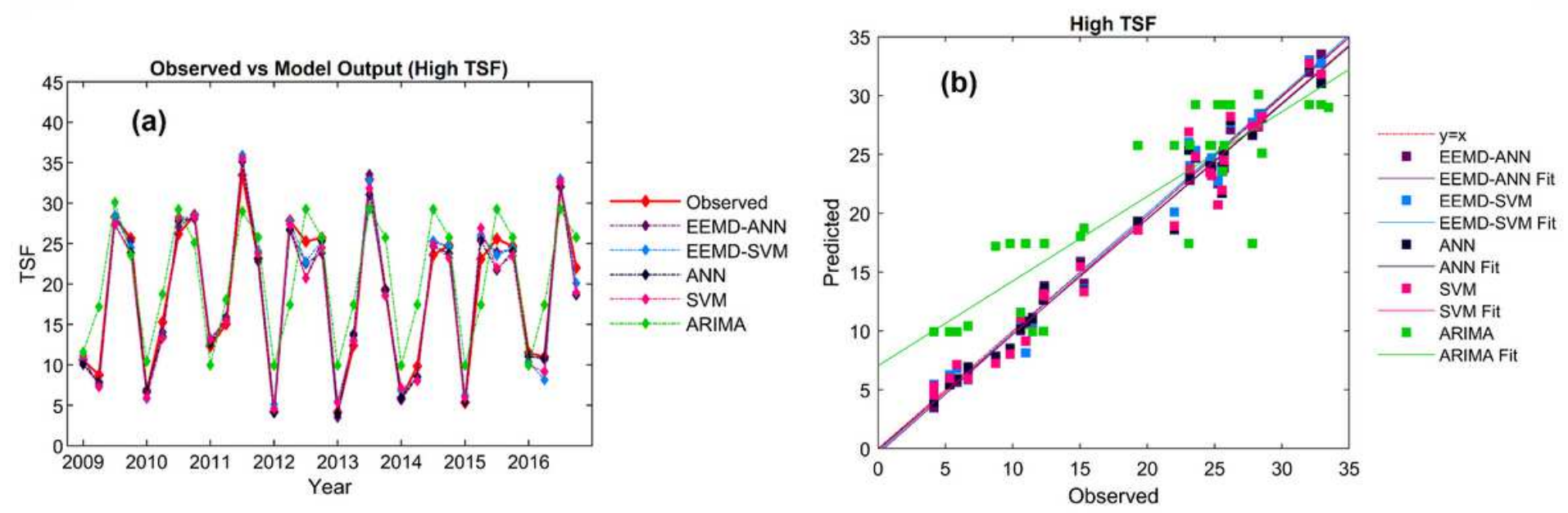

(c)

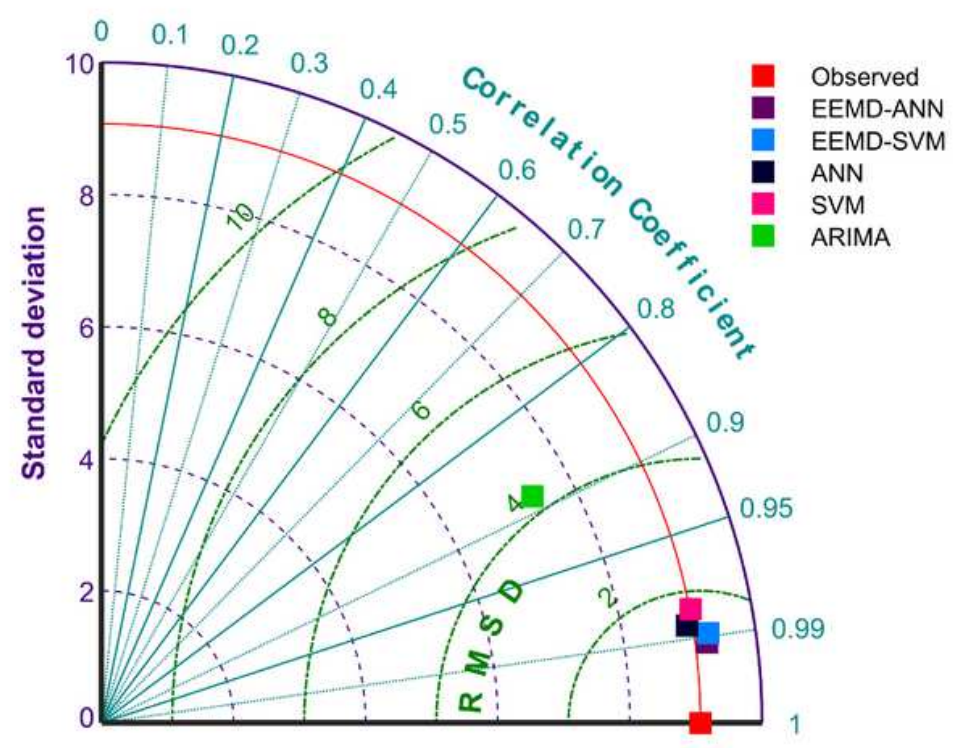

Figure 5

Observed and predicted output of the testing dataset of the high TSF series (a); scatterplot fitting of the prediction models (b); and Taylor Diagram of prediction by EEMD-ANN, EEMD-SVM, ANN, SVM, and ARIMA models (c). The deep cyan contours represent the Pearson correlation coefficient, green contours represent centered RMS error in the simulated field, and violet contours represent the Standard Deviation of the simulated pattern. 
(a)

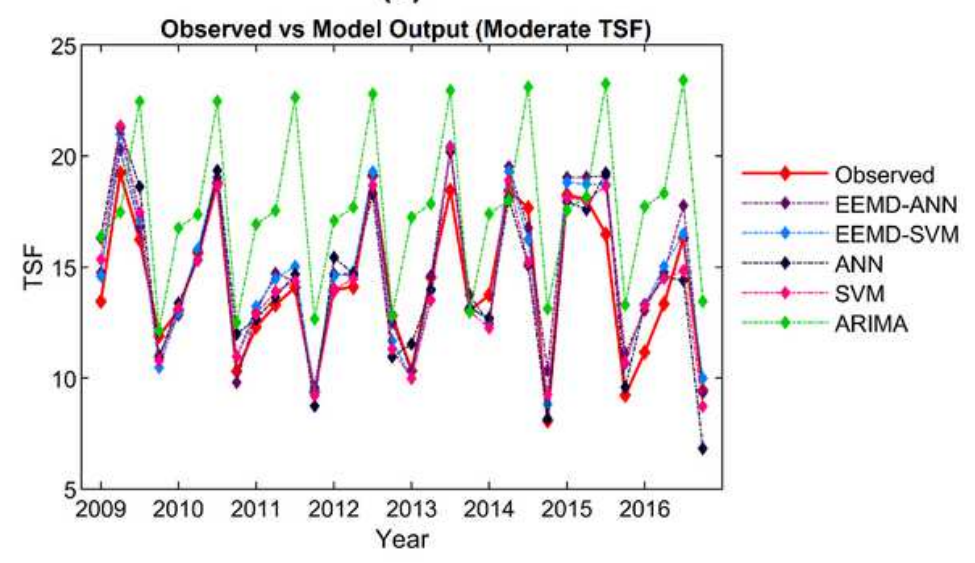

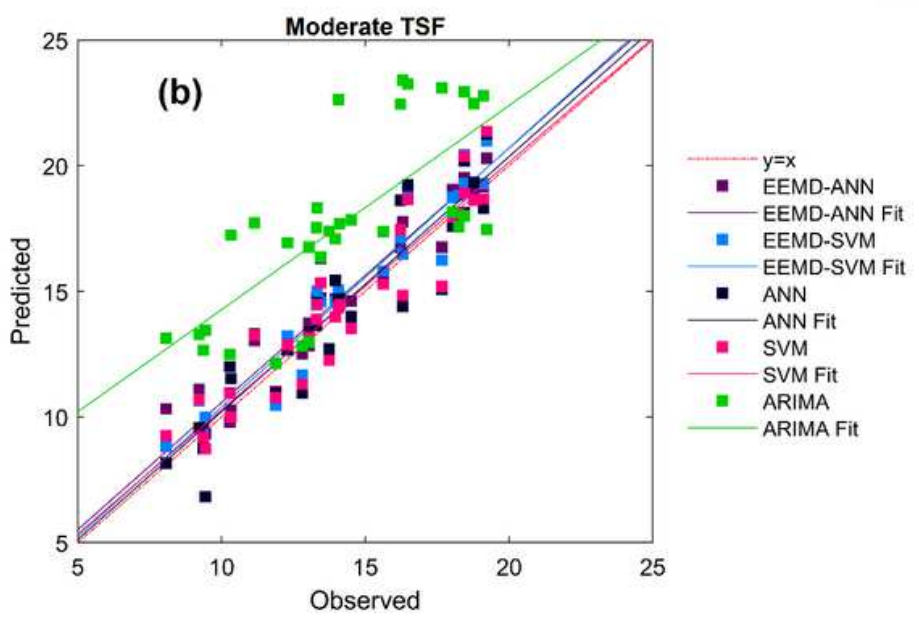

(c)

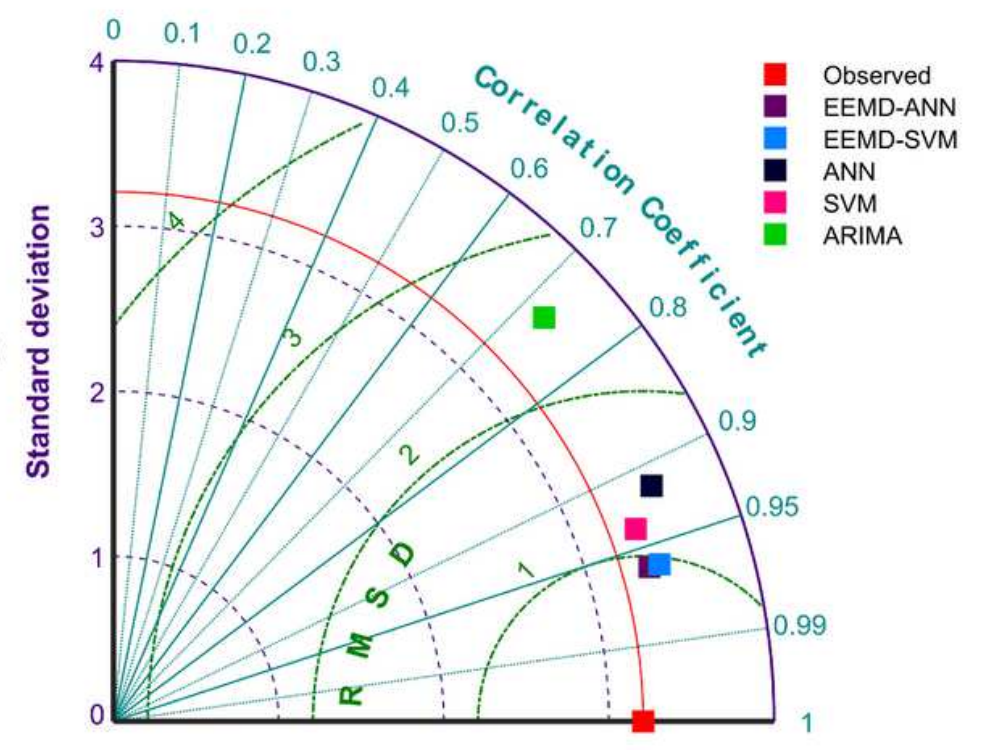

Figure 6

Observed and predicted output of the testing dataset of the moderate TSF series (a); scatterplot fitting of the prediction models (b); and Taylor Diagram of prediction by EEMD-ANN, EEMD-SVM, ANN, SVM, and ARIMA models (c). The deep cyan contours represent the Pearson correlation coefficient, green contours represent centered RMS error in the simulated field, and violet contours represent the Standard Deviation of the simulated pattern. 

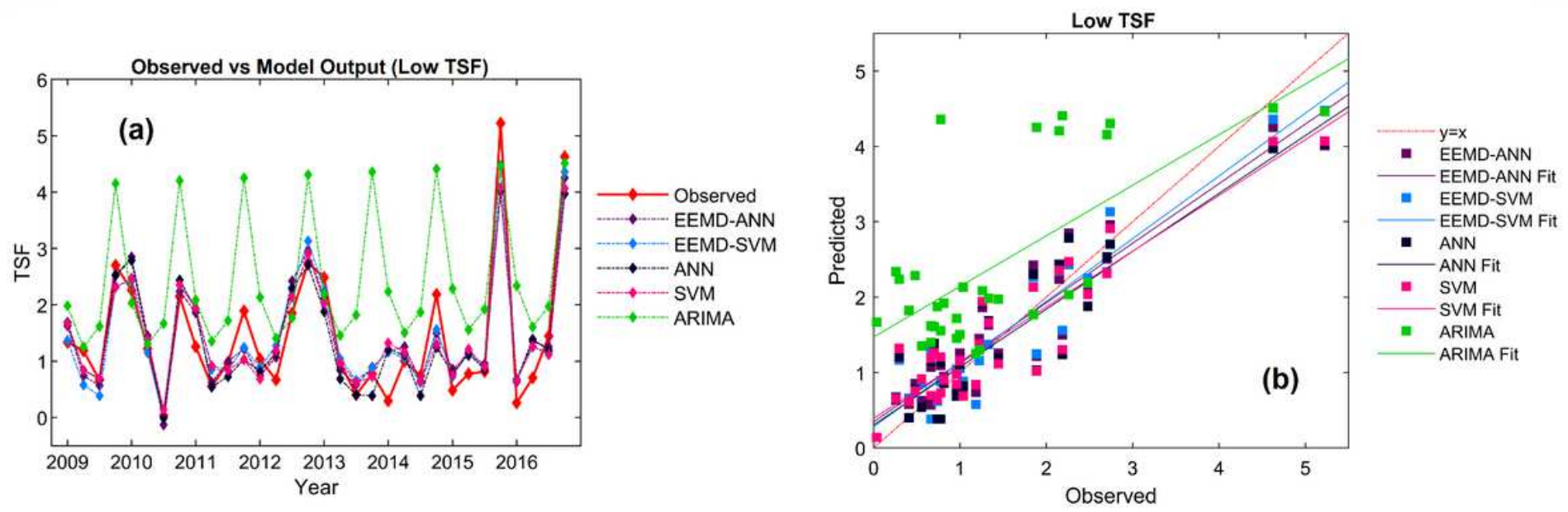

(c)

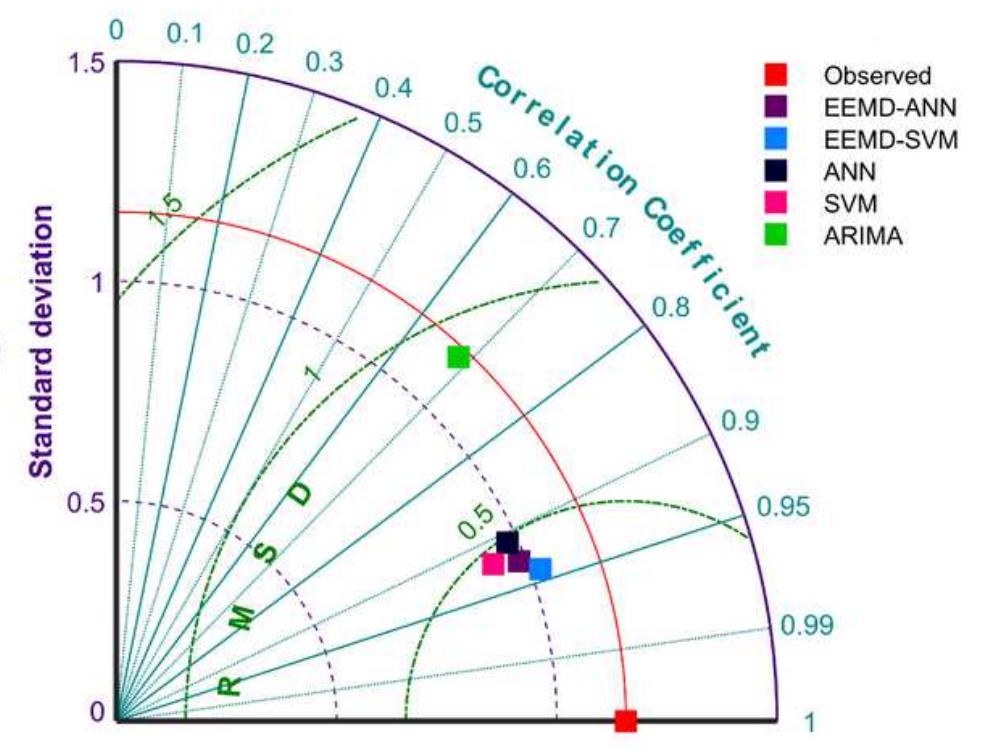

\section{Figure 7}

Observed and predicted output of the testing dataset of the low TSF series (a); scatterplot fitting of the prediction models (b); and Taylor Diagram of prediction by EEMD-ANN, EEMD-SVM, ANN, SVM, and ARIMA models (c). The deep cyan contours represent the Pearson correlation coefficient, green contours represent centered RMS error in the simulated field, and violet contours represent the Standard Deviation of the simulated pattern. 

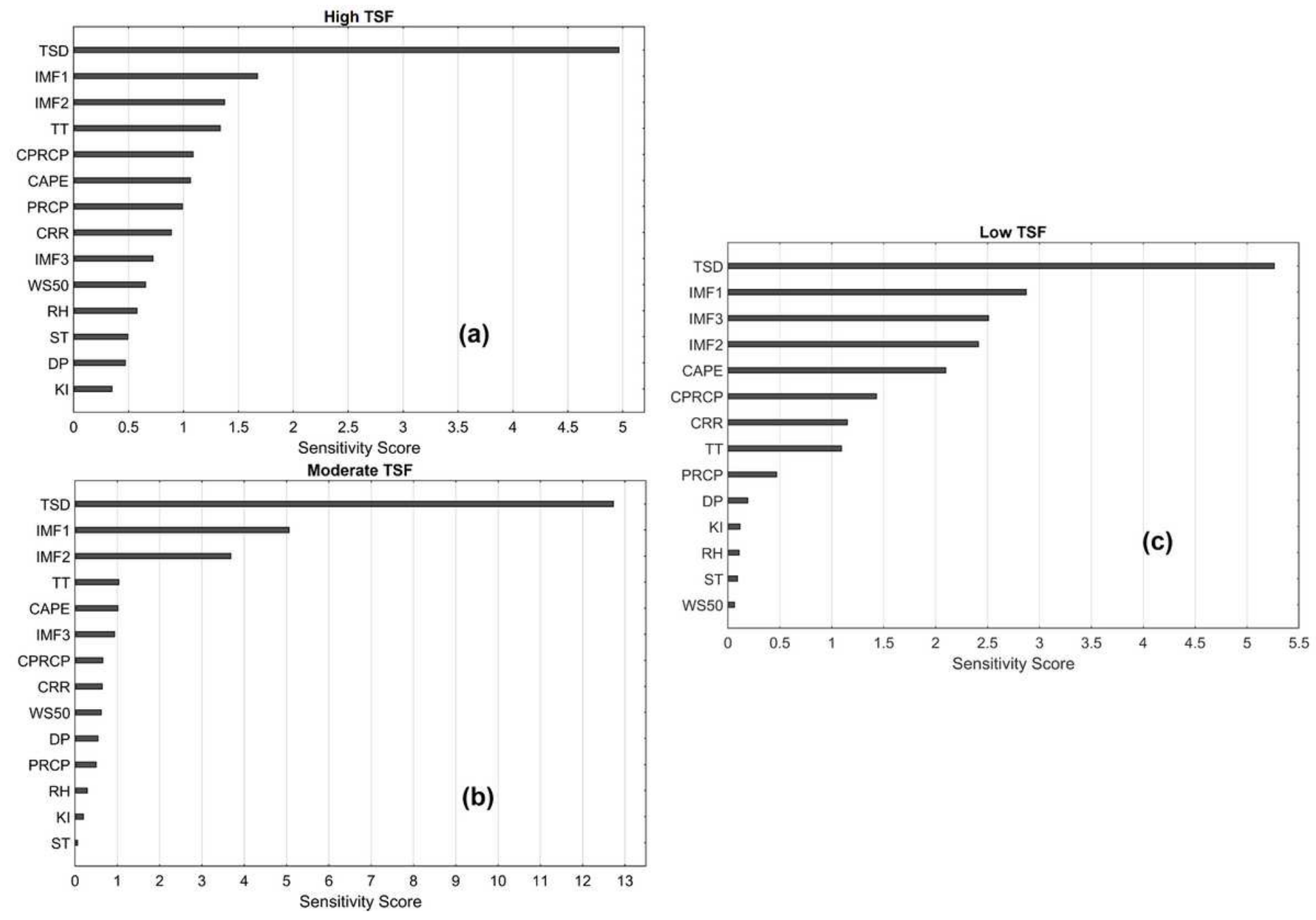

\section{Figure 8}

Sensitivity of the input parameters in building the best models in predicting high TSF (a), moderate TSF (b), and low TSF (c). 